REVIEW ARTICLE

\title{
Forty years of durability assessment of nuclear waste glass by standard methods
}

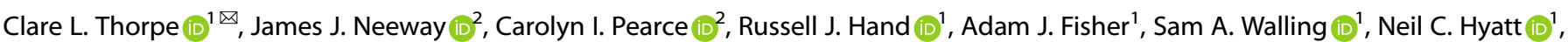

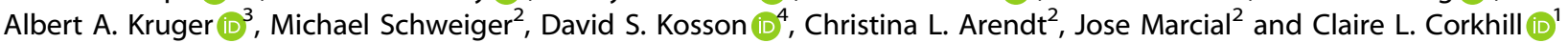

Standard methods to assess the durability of vitrified radioactive waste were first developed in the 1980's and, over the last 40 years, have evolved to yield a range of responses depending on experimental conditions and glass composition. Mechanistic understanding of glass dissolution has progressed in parallel, enhancing our interpretation of the data acquired. With the implementation of subsurface disposal for vitrified radioactive waste drawing closer, it is timely to review the available standard methodologies and reflect upon their relative advantages, limitations, and how the data obtained can be interpreted to support the post-closure safety case for radioactive waste disposal.

npj Materials Degradation (2021)5:61; https://doi.org/10.1038/s41529-021-00210-4

\section{INTRODUCTION}

Understanding the behaviour of glasses in contact with water, or water vapour, is of interest across many disciplines including archaeology, geology, waste encapsulation, construction, fibre optics, semiconductors and art. However, the main economic, technical, and regulatory, driver behind the need to estimate the corrosion behaviour of vitreous materials over very long timescales, $10^{3}-10^{6}$ years, arises from planned isolation of vitrification of radioactive wastes in subsurface repositories. This review will focus on the laboratory testing methodology developed to predict the durability of nuclear waste glasses that are typically highly durable. The methodology discussed is relevant across a wide range of nuclear and non-nuclear glass compositions including silicate, borosilicate, and phosphate glasses as well as glass ceramics.

Vitrification is the most common treatment technology for the immobilisation of high-level radioactive wastes (HLW) arising from spent fuel reprocessing, being applied since the late 1970's at facilities in Belgium, China, Germany, India, Japan, Pakistan, Russia, Slovakia, UK and USA (Table 1) $)^{1-3}$. Vitrification has also been applied to the immobilisation of lower-activity waste streams with a range of glass compositions ${ }^{4-6}$. Extensive research programmes are underway in European countries including the UK, France and Belgium, under the European $\mathrm{H} 2020$ research programmes, THERAMIN and PREDIS ${ }^{7,8}$. These programmes are considering vitrification technologies, including continuous feed joule-heated melters, and in-container vitrification using Kurion GeoMelt ${ }^{\oplus}$ Veolia Geomelt ${ }^{\oplus}$ technology ${ }^{9-13}$. Meanwhile, in the USA, a vitrification plant is shortly to begin to encapsulate low-activity waste (LAW) and, eventually, processed HLW at the Hanford Site in Washington State ${ }^{14,15}$. Most countries use alkali-borosilicate glass compositions to immobilise calcined or liquid feed reprocessing waste. However, sodium-aluminophosphate glass is used to immobilise HLW in Russia, while iron-phosphate glasses have been investigated for potential immobilisation of HLW and LAW in the USA (Table 1 ; refs. ${ }^{16,17}$ ). When optimising waste glass compositions, chemical durability is a key consideration along with melting rate to allow a fast waste throughput, waste loading, homogeneity, and processing ease (melting temperature, viscosity, etc.). Waste loading in sodium aluminium borosilicate compositions typically ranges between 15 and $30 \mathrm{wt} \%$ oxides and is dependent on the solubility of waste elements in the base glass (Table 1).

It is the consensus view in many countries that have produced nuclear waste, from military or civil nuclear power operations, that the long-term management of these materials is best performed within a subsurface disposal facility ${ }^{18}$. The specific disposal concept employed depends on different factors dictated largely by the type and activity of the waste, the available geology and hydrogeology. Although the disposal facilities will be designed to isolate radioactive waste from the biosphere for at least hundreds of thousands of years, it is inevitable that groundwater will ingress the facility, slowly degrading the engineered barriers (over $1000 \mathrm{~s}$ of years) and eventually contacting the waste. Upon contact with water, vitrified waste will begin to dissolve and release radionuclides into the near-field environment. Quantification of the dissolution rate of the glass under conditions relevant to the specific subsurface environment in question is, therefore, critical for the development of a robust safety case for disposal.

Deep geological disposal (ranging from 200 to $\sim 1000 \mathrm{~m}$ ) is the preferred option for the disposal of $\mathrm{HLW}^{19}$. Lower-activity wastes are either destined for co-disposal with HLW, or for near-surface ( $\sim 15$ to $\sim 200 \mathrm{~m}$ deep) disposal in separate facilities, such as the Integrated Disposal Facility (IDF) at the Hanford Site, USA. Deep geological disposal concepts rely on a 'multi-barrier' or 'engineered barrier' approach, where radionuclides are isolated from the environment by multiple layers of containment (Fig. 1). These layers include: the waste form, which is designed to be highly durable and to corrode slowly over the time period for which the waste remains radioactive; the canister, typically composed of a metal, sometimes with an 'overpack' to provide physical and chemical stability; the backfill or buffer material, designed to surround the canister; and, finally, the host rock itself, which provides a long transport pathway should any radionuclides become solubilised within groundwater ${ }^{20,21}$.

\footnotetext{
${ }^{1}$ Department of Materials Science and Engineering, University of Sheffield, Sheffield, UK. ${ }^{2}$ Pacific Northwest National Laboratory, Richland, WA, USA. ${ }^{3}$ Office of River Protection, U. S. Department of Energy, Richland, WA, USA. ${ }^{4}$ Department of Civil and Environmental Engineering, Vanderbilt University and CRESP Nashville, Nashville, TN, USA.

email: clare.thorpe@sheffield.ac.uk
} 
C.L. Thorpe et al.

Table 1. List of vitrification facilities by country and representative compositions of some typical glass formulations associated with those facilities.

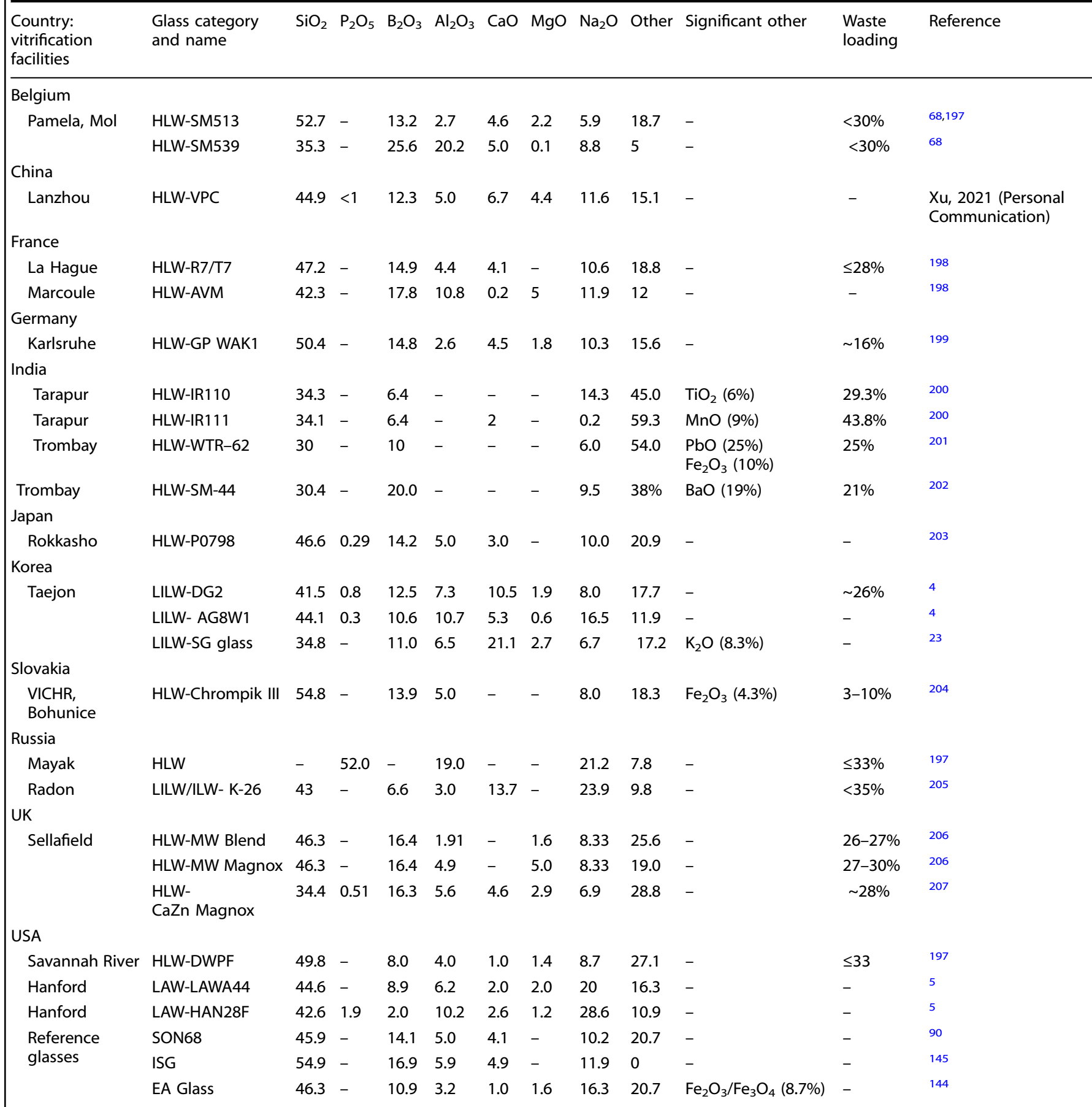

The geochemistry of deep disposal environments is typified by low hydraulic conductivity anoxic conditions with initially high, but slowly decreasing temperatures and radiation fields, and changing aqueous chemistry as the barrier materials degrade. The complex nature of this environment creates a significant challenge in determining the mechanisms and rates of glass dissolution. Current uncertainty in predicting the long-term release rate of radionuclides from glass has resulted in countries adopting a conservative approach using the most rapid dissolution rate (known as the forward rate, see section 'Glass dissolution: a summary of key mechanisms and terms') as the source term for input into safety case models ${ }^{22}$.
In near-surface repositories, the host rock, or sediment, plays a lesser role in isolating the waste than in deep disposal facilities. The waste form and engineered barrier play a critical role in making sure performance criteria, designed to ensure human safety, are met. One example of a near-surface facility is the IDF for vitrified LAW and other permitted low-activity wastes (e.g., cementitious materials) at the Hanford site, USA. The IDF is designed to isolate waste from the groundwater and the capped facility is located above the water table from which leachate will be monitored ${ }^{14}$. Vitrified LAW will not contain longer-lived and more radiotoxic actinide elements (e.g., $\mathrm{U}, \mathrm{Np}$ ) but will immobilise a combination of short and long-lived fission 


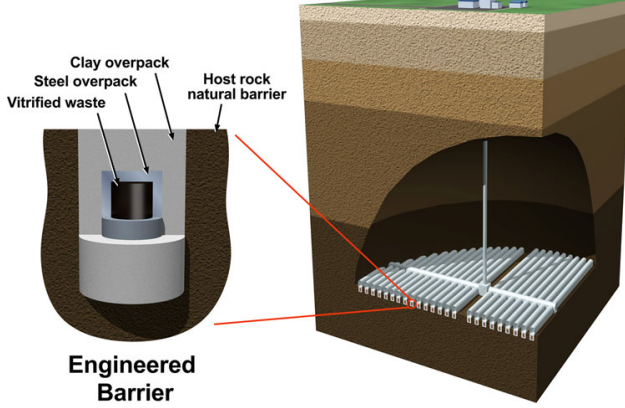

Fig. 1 Geological disposal of vitrified radioactive waste. Diagram of a generic geological disposal facility for vitrified radioactive waste showing the multi-layered engineered barrier.

products $\left({ }^{60} \mathrm{Co},{ }^{99} \mathrm{Tc}\right.$ and ${ }^{129} \mathrm{I}$ and small amounts of ${ }^{154} \mathrm{Eu},{ }^{137} \mathrm{Cs}$ and ${ }^{90} \mathrm{Sr}$ ), as well as toxic metals ${ }^{14}$. Another example in Korea is the Wolsong Low and Intermediate Level Radioactive Waste Disposal Centre; a silo type repository situated at $130 \mathrm{~m}$ below sea level in granodiorite geology. Low-level wastes are currently accepted and co-disposal of vitrified wastes are planned ${ }^{4,23}$. Near-surface environments are characterised by lower temperatures as wastes are non-heat generating and more susceptible to environmental change, for example, changes in groundwater chemistry and fluctuations in the water table.

The purpose of this review is to collate the wealth of knowledge gained over the last four decades specifically on the application and interpretation of data from standardised test methods designed to assess the durability of nuclear waste glasses. A comprehensive review was last published as the Waste Forms Technology and Performance: Final Report (N2011) ${ }^{24}$ whilst comparisons of selected tests appear in a limited number of journal articles for example Strachan ${ }^{25}$, Inagaki ${ }^{26}$, and Fournier et al. ${ }^{27}$. This article builds on previous work with the addition of recently used methods, the personal practical experience of the authors and a review of standard tests as applied to a single model glass. An assessment of durability methods is timely to support both the widening of nuclear waste glass compositions for the immobilisation of lower-activity wastes and the increasing need for underpinning data for use in safety cases and safety/ performance assessment for current and future disposal sites. Due to the current dominance of silicate glass compositions (Table 1) and limited availability of durability test, data performed on phosphate glasses this review has focused on test response to silicate glasses only. Section 'Glass dissolution: a summary of key mechanisms and terms' summarises the general mechanisms of silicate glass dissolution will be briefly summarised and a glass dissolution glossary will be provided to standardise the definitions for glass dissolution terminology used within this paper. In the section 'Standard methods to determine glass dissolution', a history of standardised and commonly applied accelerated test methods for glass durability assessment are discussed in the context of their original design purpose and current use, which is not always the same. For example, tests originally designed for maintaining product consistency have been adapted and are now used in the academic literature to estimate long-term glass behaviour. Methods are grouped according to the current mechanistic understanding of glass dissolution with reference to the stage of glass dissolution that each test method measures. In the section 'Evaluation of accelerated durability methods and some common issues and challenges', common challenges in the practical application of these methods are then detailed along with how these challenges have historically been addressed. Section 'Application of standard methods to a standard alkali-borosilicate glass' comprises a review of the available data where standard methods have been applied to the international standard alkali-borosilicate glass, the International Simple Glass (ISG), allowing comparison of the dissolution rate data obtained from a wide range of test methods. The concluding section 'The future of accelerated glass dissolution methods: a perspective' offers a perspective of what has changed in 40 years since the first accelerated dissolution test was developed, the constraints of laboratory-based accelerated methodologies, the need to validate them against real-time dissolution in complex systems, and how glass dissolution rates fit within the wider safety case for subsurface disposal of radioactive wastes.

\section{GLASS DISSOLUTION: A SUMMARY OF KEY MECHANISMS AND TERMS}

Research pertaining to glass durability was in its infancy in the 1980 s with many early studies drawing from the vast knowledge of silicate mineral dissolution available within geological literature. In the proceeding 40 years, the nomenclature used to describe the dissolution phenomenon has evolved in parallel with an understanding of the dissolution mechanisms and a wide range of definitions to describe various behaviours and processes. To date, there does not exist one definitive set of these definitions and, as such, certain terms and phrases have been, albeit unknowingly, used interchangeably providing some confusion in the literature. Table 2 presents a comprehensive glossary of common terms used in glass dissolution with clear definitions as used in this paper.

Glass corrosion is a complex process since glass alters at various rates across different stages and under wide-ranging environmental conditions. The dissolution kinetics of alkali-borosilicate glass over time can be described as a function of glass composition, temperature, $\mathrm{pH}$ and solution chemistry. General mechanisms occur regardless of the glass composition and are described comprehensively in works such as (Varshneya ${ }^{28}$ (Chapter 17.4); Ojovan et al. ${ }^{29}$ (Chapter 23); Strachan ${ }^{30}$; Gin et al. $\left.^{31}\right)$. These comprise two main mechanisms of chemical attack: the leaching of mobile ions from the glass network driven by $\mathrm{H}^{+} / \mathrm{H}_{3} \mathrm{O}^{+}$and the breakdown of the glass network driven by $\mathrm{OH}^{-}$.

Extensive published studies of nuclear glass corrosion describe the process in five stages, or kinetic rate regimes, each with a different rate-limiting mechanism ${ }^{32}$. This approach is based on experimental observations of the corrosion kinetics, simply determined in most cases by measuring the concentration of solubilised elements (particularly boron) from the glass in the surrounding solution. The five stages are (1) interdiffusion; (2) initial rate; (3) rate drop; (4) residual rate and (5) rate resumption (not always observed). However, recent consensus considers only three of the five as kinetic rate regimes, shown in Fig. $2 a$, b ${ }^{31,33}$, as interdiffusion and rate-drop regimes are not formal kinetic stages. Interdiffusion occurs constantly throughout glass corrosion, on the scale of $<10^{-15} \mathrm{~m}^{2} \mathrm{~s}^{-1}$, no matter the stage of corrosion, but acts alone for only very small time periods ${ }^{32,34}$. The rate-drop regime is merely a transition between the initial and residual rate, during which time the solution is subject to increasing silica concentration $^{35}$, which allows for the formation of an alteration layer on the surface that could impact continued corrosion ${ }^{33,36}$. Hence, glassalteration rates will be referred to in three stages. All stages are described briefly below and the reader is directed to Frugier et al. ${ }^{32}$, Fournier et al. ${ }^{37}$ and Gin et al. ${ }^{31}$ for a detailed description of each stage.

The initial rate regime (stage l), is defined as glass dissolution that occurs under 'far from equilibrium' conditions before saturation of the leaching media. During this time, rapid diffusion/interdiffusion occurs before the congruent dissolution of the silicate network releasing mobile cations (e.g., $\mathrm{Li}^{+}, \mathrm{Na}^{+}, \mathrm{K}^{+}$) via ion exchange with $\mathrm{H}^{+} / \mathrm{H}_{3} \mathrm{O}^{+}$from the contacting solution and leaving the near surface of the glass depleted with respect to these elements ${ }^{31}$. Meanwhile, the slower breakdown of the glass network (Si-O/B-O bonds) by 
Table 2. A glass dissolution glossary, defining keywords and phrases of relevance to the radioactive waste glass dissolution community.

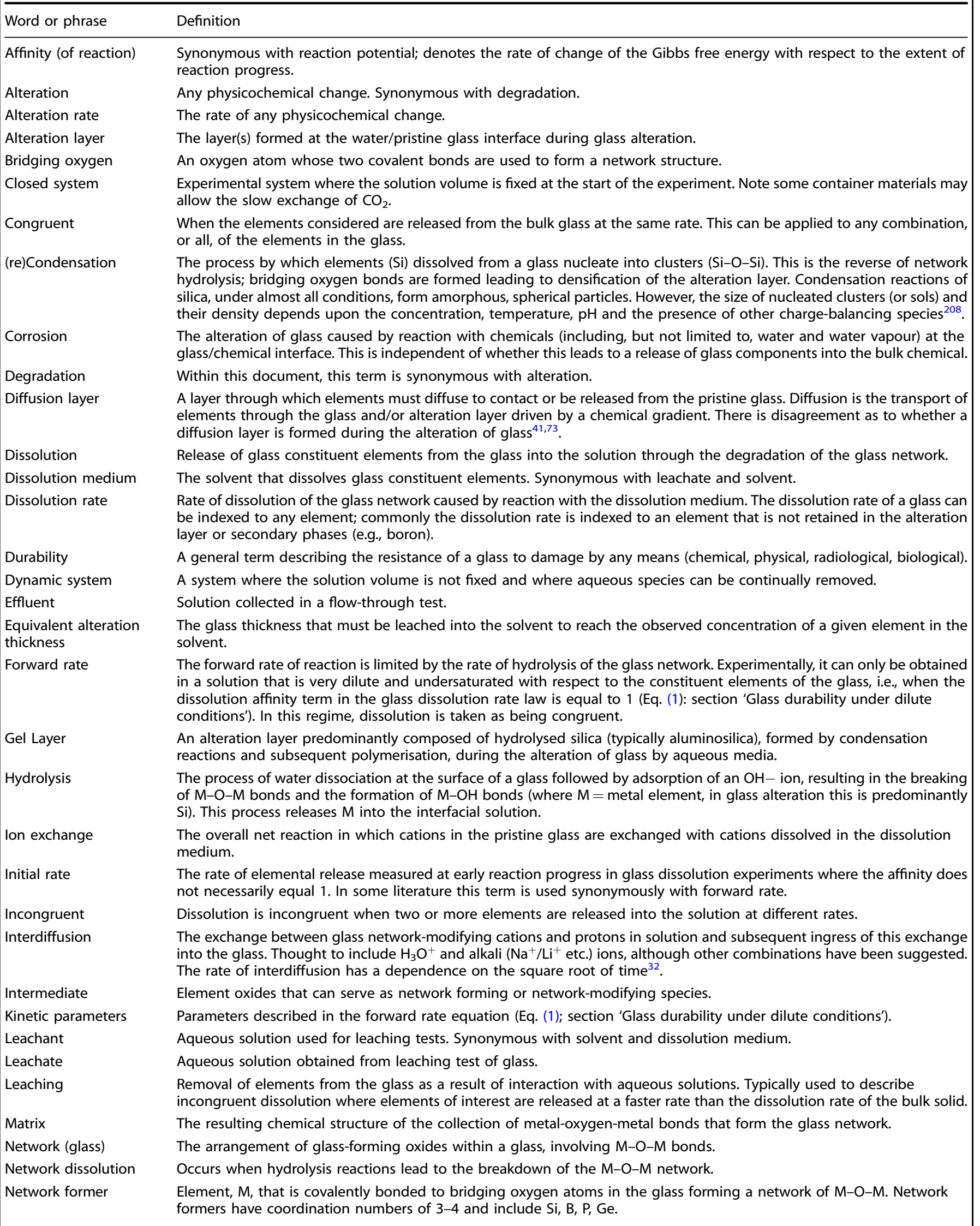




\begin{tabular}{|c|c|}
\hline Word or phrase & Definition \\
\hline Network modifier & $\begin{array}{l}\text { Elements (e.g., } \mathrm{Na}, \mathrm{Li} \text { ) added in the glass that is attached to the } \mathrm{M}-\mathrm{O}-\mathrm{M} \text { framework by ionic bonds with non-bridging } \\
\text { oxygen atoms. }\end{array}$ \\
\hline Non-bridging oxygen & $\begin{array}{l}\text { A localised defect in the glass network involving oxygen bonded to one network former and one network modifier. Non- } \\
\text { bridging oxygens are formed by the introduction of network modifiers. }\end{array}$ \\
\hline $\begin{array}{l}\text { Normalised } \\
\text { dissolution rate }\end{array}$ & $\begin{array}{l}\text { Ratio of the measured release rate of glass constituents }\left(c_{i}\right) \text { to its mass fraction in the glass }\left(f_{i}\right) \text {, the ratio of the surface area } \\
\text { of glass to the volume of solution }(S A / V) \text { and time }(t) . N L R_{i}=c_{i}\left(\text { sample) } /\left(f_{i}\right) \times(S A / V) /(t)\right.\end{array}$ \\
\hline Open system & $\begin{array}{l}\text { Experimental system, often open to the atmosphere, where the solution volume is not fixed. Instead, a flowing solution or } \\
\text { solution replacement removes dissolved elements from the system. }\end{array}$ \\
\hline Polymerisation & $\begin{array}{l}\text { The chemical process of smaller structural units joining together to form a glass network. In this document, polymerisation } \\
\text { is used to describe both the extent of network connectivity within a glass, in addition to the process of silica condensation } \\
\text { that occurs to form a gel layer. }\end{array}$ \\
\hline Passivation & Where the formation of an alteration layer is correlated with a decrease in the overall alteration rate of the glass. \\
\hline Rate drop & $\begin{array}{l}\text { A decrease in the dissolution rate from the initial rate. This may occur upon the formation of a gel layer and/or changes in } \\
\text { solution affinity. The transition between the rate-drop regime and the residual rate regime was defined in Gin et al. }{ }^{209} \text { as } \\
\text { the turning point in a plot of } \mathrm{r} \text { (boron) vs the activity of } \mathrm{H}_{4} \mathrm{SiO}_{4} \text {. }\end{array}$ \\
\hline Rate resumption & $\begin{array}{l}\text { An increase in the alteration rate following the rate drop in a closed system }{ }^{32} \text {. Synonymous with stage III (in the three-stage } \\
\text { model; } ; 1,33 \text { ) or stage } V \text { (in the five-stage model; }{ }^{32} \text { ). This behaviour appears to be related to the massive precipitation of } \\
\text { crystalline (zeolite and clay) secondary phases. }\end{array}$ \\
\hline Residual rate & $\begin{array}{l}\text { The dissolution rate measured upon the attainment of silica saturation in solution and after the rate drop. This rate is } \\
\text { always lower than the forward rate, but in certain circumstances is equal to the initial rate }{ }^{210,211} \text {. In a closed system, this } \\
\text { rate is generally slowly decreasing or remains constant. }\end{array}$ \\
\hline Saturated solution & $\begin{array}{l}\text { A solution in which no more solid (glass, gel layer or alteration product) can be dissolved into the solvent. For example, if a } \\
\text { solution is saturated with respect to } \mathrm{SiO}_{2} \text { then no more } \mathrm{Si} \text { will be released into solution although glass may continue to } \\
\text { react and } \mathrm{SiO}_{2} \text { gel may form instead. }\end{array}$ \\
\hline Stage II & Residual rate regime. In earlier literature referred to as stage $\mathrm{IV}^{32}$. \\
\hline Stage III & $\begin{array}{l}\text { Stage of accelerated corrosion following the relatively low residual rate. Often referred to as rate resumption. In earlier } \\
\text { literature referred to as stage } \mathrm{V}^{32} \text {. }\end{array}$ \\
\hline Stagnant & $\begin{array}{l}\text { Dissolution environments with low or zero flow; the solution chemistry may be strongly affected by components leaching } \\
\text { out of the glass. }\end{array}$ \\
\hline Steady state & $\begin{array}{l}\text { A condition of a dynamic system wherein one or more of the system variables does not perceptibly change with time. } \\
\text { Within the context of glass alteration, often used when describing the residual rate. }\end{array}$ \\
\hline Surface area & $\begin{array}{l}\text { (i) Reactive surface area- that area of glass available to react, (ii) geometric surface area-surface area as estimated by } \\
\text { geometric shapes, (iii) BET measured surface area refers to the total area of the glass surface that is open to the physical } \\
\text { adsorption of gas molecules. This includes cracks which are connected to the external surface. }\end{array}$ \\
\hline Transition state theory & $\begin{array}{l}\text { A theoretical method for calculating reaction rates based on a statistical mechanics calculation of the thermodynamic } \\
\text { properties of the potential energy surface separating the reactants and products of a chemical reaction. A derivation of the } \\
\text { mineral dissolution rate law }{ }^{212} \text { specifically used to describe silicate dissolution } 213,214 \text {. }\end{array}$ \\
\hline Validation & The process of ensuring that a model accurately simulates the behaviour of the system that is modelled. \\
\hline
\end{tabular}

hydrolysis begins concurrently and becomes the rate-limiting process ${ }^{38}$. Under dilute conditions, at a fixed $\mathrm{pH}$, congruent dissolution of the silicate/borosilicate network is known as the 'forward rate' of dissolution providing solution feedback is avoided and the concentrations of elements in solution, from the glass, are effectively zero in solution (see section 'Glass durability under dilute conditions'). The 'initial rate' is measured from the linear elemental release observed during early reaction progress in glass dissolution experiments prior to the rate drop. The term 'initial rate' has also been applied to ion-exchange-dominated dissolution, which may persist over long timescales under dilute, low temperature, moderate $\mathrm{pH}$ conditions ${ }^{39}$.

The rate drop regime, begins when sufficient hydrolysed silica is available to form a silica gel. This occurs either by reorganisation of the silicate network via hydrolysis/condensation reactions ${ }^{33,38,40}$ or by dissolution/reprecipitation reactions ${ }^{41,42}$. This is a passivating effect as water must diffuse through the gel layer to contact the pristine glass (Fig. 2b). Glass corrosion continues via diffusion of elements through, and incorporation of elements into, the gel layer. 


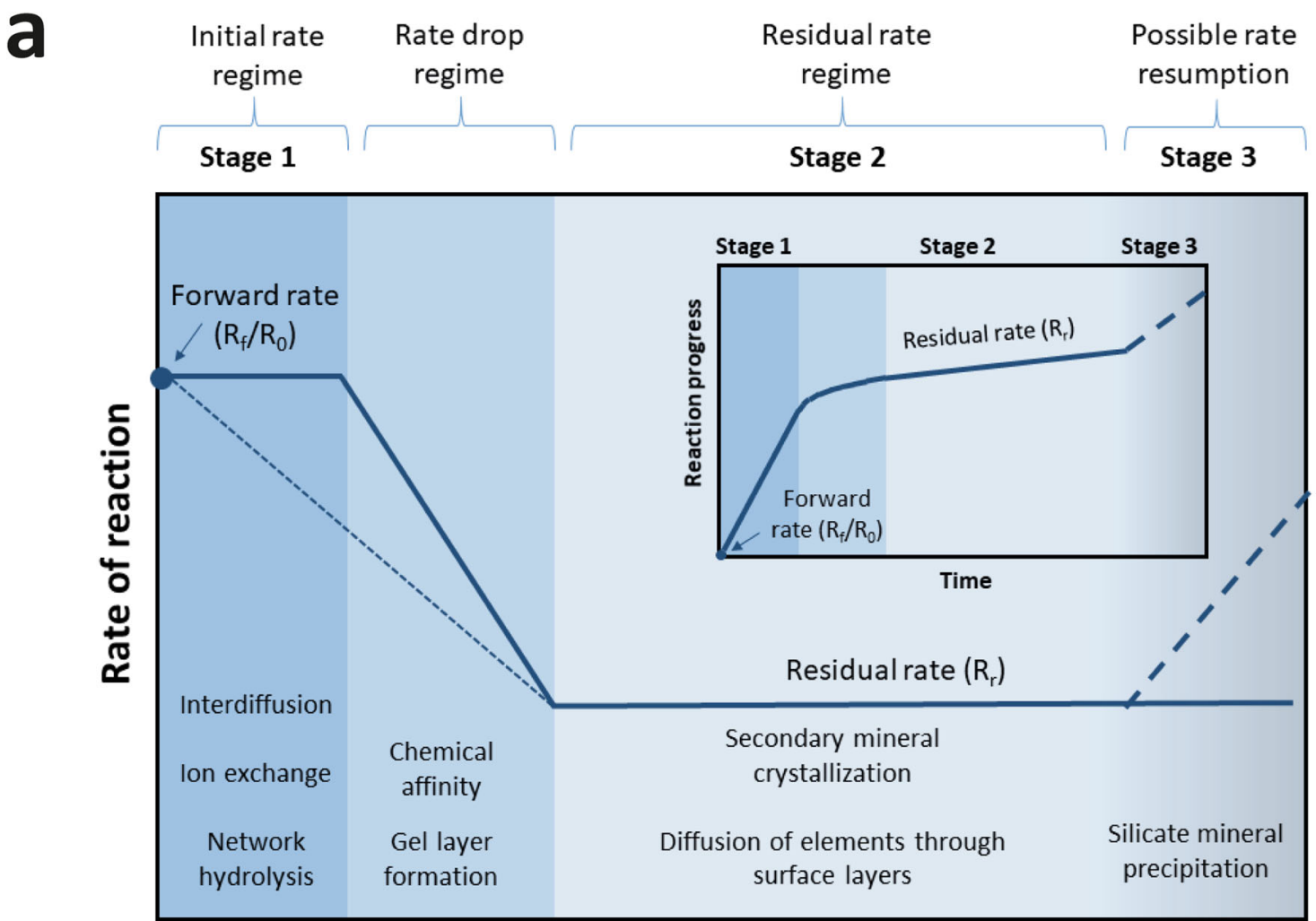

b

\section{Initial rate regime}

(1) Diffusion of
$\mathrm{H}_{3} \mathrm{O}^{+}$ions into
the glass

(2) $\mathrm{H}_{3} \mathrm{O}^{+}$ions displace network modifying alkali ions (e.g Na+, $\left.\mathrm{Li}^{+}\right)$

(3) The silicate network begins to breakdown. Si is released leaving a hydrolysed surface silicate layer

(1)

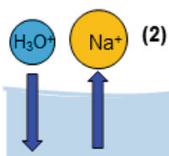

(3)

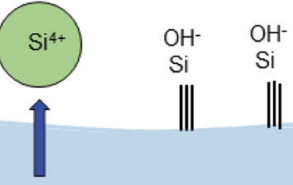

(1) and (2) continue, but more slowly

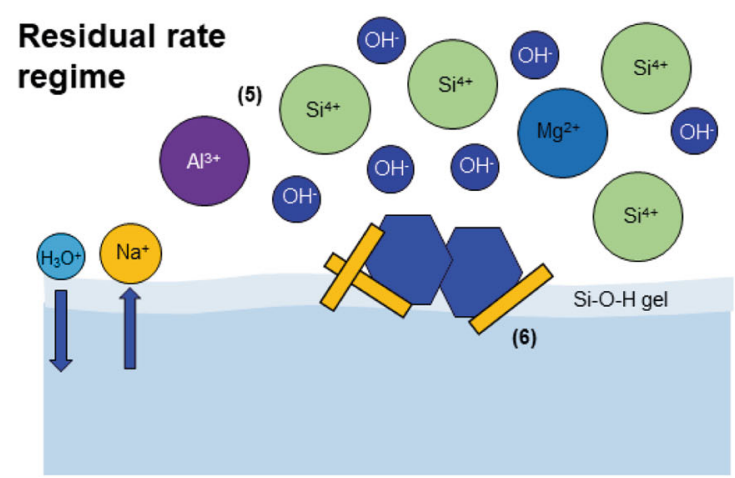

\section{Rate drop regime}

(4) Re-organisation of surface silicate layer into a silica gel. Silica gel can incorporate elements from glass or solution for charge balancing purposes.

Porosity dependent on gel composition and solution $\mathrm{pH}$.

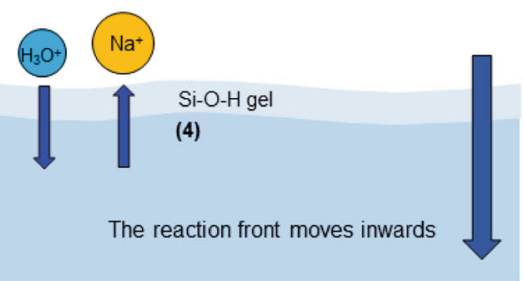

(5) The water layer at the surface becomes saturated with respect to the other elements that have leached from the glass

(6) Corrosion products are precipitated

Fig. 2 Summary of rates and mechanisms of glass dissolution. a Glass dissolution described as three stages. Stage 1 (characterised by interdiffusion, ion exchange and hydrolysis of the silicate network), stage 2 (characterised by the diffusion of elements through a gel layer and secondary phase crystallisation), and stage 3, (a potential rate increase driven by silicate mineral precipitation). b simplified diagram summarising the key processes that occur in borosilicate glass dissolution Note that exact speciation of metal ions in solution will be controlled by $\mathrm{pH}$, for example, $\mathrm{Si}^{4+}$ may be $\mathrm{H}_{2} \mathrm{SiO}_{4}{ }^{2-} / \mathrm{H}_{3} \mathrm{SiO}_{4}^{-} / \mathrm{H}_{4} \mathrm{SiO}_{4}$. 
In the residual rate regime (stage II), the dissolution rate is several of orders of magnitude slower than the initial rate and is controlled by the evolution of the silica gel layer that can restructure, densify and/or precipitate secondary phases at the bulk solution/altered glass interface ${ }^{31,32,38}$. The rate of glass dissolution in this regime depends upon the rate of diffusion of water to the glass surface, and of glass constituent elements to the solution, through this layer. The rate of glass dissolution also depends upon the solution chemistry and the alteration layer composition. Most notably the precipitation of secondary silicate phases (e.g., aluminosilicate zeolites) can result in a phenomenon termed rate resumption (stage III). The rate increase mechanism is not fully constrained, but it is thought to occur when aluminosilicate phases (exclusively zeolites) scavenge silica from solution, giving rise to silica undersaturated conditions that drive further dissolution ${ }^{43-45}$, or that zeolite precipitation 'destabilises' the gel layer ${ }^{46,47}$. In recent experiments, a stage-three-like increase in the elemental release was observed but was found to derive from the formation of new cracks, and resulting exposure of fresh surfaces, rather than from changes in glass surface chemistry ${ }^{48}$.

Under conditions where the relative humidity is $<100 \%$ (e.g., the pressurised unsaturated flow, or PUF, test), the same general mechanisms apply; however, there may be greater retention of alkali elements, more rapid formation of crystalline phases and increased sensitivity to surface defects ${ }^{49}$.

\section{STANDARD METHODS TO DETERMINE GLASS DISSOLUTION}

Accelerated durability assessment methods for alkali-borosilicate glasses were first developed when these materials were adopted as the preferred immobilisation matrix for radioactive waste ${ }^{50-52}$. The standardised test protocols reviewed in this work are those adopted by an accredited organisation to generate a clearly defined response for a specific material or range of materials. The review also includes non-standardised tests described extensively in the literature. Accredited organisations include ASTM International (ASTM), American National Standards Institute (ANSI), the Materials Characterisation Centre (MCC), the International Atomic Energy Agency (IAEA), the Environmental Protection Agency (EPA) and the International Organisation for Standardisation (ISO). Initially, these tests were important in waste form design and qualification for operations: to 'accept' or 'reject' glass compositions based on a pre-determined 'acceptable' test response under relevant conditions. Acceptance criteria tend to draw a compromise between waste loading, manufacturing logistics and an assessment of the chemical durability. Most of the standard methods described in this review were developed to provide a quick and inexpensive method to rank new glass compositions by comparison to existing or standard waste form materials, rather than to provide definite dissolution rates that can be used in longterm performance predictions.

Since several geological disposal facilities are nearing final construction, or are under-going regulatory scrutiny prior to waste disposal, the requirement to understand long-term glass behaviour in disposal environments has become increasingly important. Alkali-borosilicate glasses were first developed a little over 100 years ago, so understanding of their long-term behaviour must be inferred from the study of glasses that have been in existence for longer time periods. Silicate glasses, arising from both geological and archaeological sources, have been studied for this purpose (section 'Validation of glass testing methodology and applicability to complex natural environments' and references therein). However, due to differences in composition and burial environment, no perfect analogue for vitrified nuclear waste in a repository setting exists. As an alternative, the type of short-term accelerated dissolution experiments employed for waste acceptance has been adapted to provide information on long-term glass durability and data useful in performance assessment.
Input of glass testing methodology into the safety case/safety assessment for long-term disposal is discussed in more detail in the section 'The future of accelerated glass dissolution methods: a perspective'.

In the following section, the methods that have been widely applied to vitrified nuclear waste (in particular alkali-borosilicate glass) are reviewed, from tests first developed exactly 40 years ago to protocols currently under development.

\section{A history of glass durability methodology}

The drive to create standardised test protocols to allow direct comparison of dissolution rates between glasses began in earnest in the early 1980's. There existed general leach tests for radioactive waste solids $s^{53}$ but, as the idea of geological disposal of radioactive waste gained momentum, the US Office of Nuclear Waste Isolation stated the requirements to quantify glass dissolution rates, alongside other properties. The first chemical durability tests developed specifically for nuclear waste glass were proposed by the Materials Characterisation Centre (MCC) (PNNL, USA), with support from the Commission of European Communities ${ }^{54}$, and the IAEA-recommended ISO 6961 standard for the Long-Term Leach Testing of Solidified Radioactive Waste Forms. The MCC developed five different methods (MCC protocols 1-5), with each protocol intended to be conducted in the same three reference solutions, including distilled water; WIPP (Waste Immobilisation Pilot Plant) Brine $A$; and a tuff groundwater representative of Yucca Mountain, Nevada. These methods were performed at specific temperatures for easy comparison between glasses and laboratories. Glass scientists have since modified and improved upon these standard protocols to create a framework of methods designed to study glass corrosion across a range of temperatures, geochemical conditions and flow rates (Fig. 3 and Table 3). The timeline for the development of the most commonly used glass dissolution tests over the last four decades is shown in Fig. 3.

While this review details the most commonly reported glass durability methods, it should be noted that there exist many other non-standard or hybrid tests, manipulations of the above methods, and one-off methods developed for a specific experiment or glass type. In one example, Abdelouas et al. ${ }^{55}$ first exposed glass to water vapour prior to the liquid alteration. In another example, Chinnam et al. ${ }^{56}$ investigated glass corrosion in a partially immersed system, where half the glass sample was exposed to a saturated solution, whilst the other half was in contact with a water film formed by the condensation of water vapour.

\section{Glass durability under dilute conditions}

Maintaining dilute conditions is an essential pre-requisite for the determination of the 'forward rate' of glass dissolution. The forward dissolution rate, $r_{0}$, is measured when the concentration/ activity of dissolved elements in solution is effectively $0 \mathrm{~mol} / \mathrm{m}^{3}$ and dissolution occurs independently of solution feedback. At $r_{0}$, intrinsic kinetic parameters of the glass can be derived using the rate equation (Eq. (1): see refs. ${ }^{30,35,57}$ ):

$r_{i}=k_{0} v_{i} a_{H^{+}}^{ \pm n} \exp \left(\frac{-E_{a}}{R T}\right)\left[1-\left(\frac{Q}{K_{g}}\right)^{\sigma}\right]$

where $r_{i}$ is the dissolution rate based on element $i\left(\mathrm{~g} \mathrm{~m}^{-2} \mathrm{~d}^{-1}\right), k_{0}$ is the intrinsic rate constant $\left(\mathrm{g} \mathrm{m}^{-2} \mathrm{~d}^{-1}\right), v_{i}$ is the stoichiometric coefficient for element $\mathrm{i}, a_{H+}$ is the hydrogen ion activity, $\pm \eta$ is the $\mathrm{pH}$ power-law coefficient, $E_{a}$ is the apparent activation energy $\left(\mathrm{J} \mathrm{mol}^{-1}\right), R$ is the ideal gas constant $\left(8.314 \mathrm{~J} \mathrm{~mol}^{-1} \mathrm{~K}^{-1}\right)$, and $T$ is the absolute temperature $(\mathrm{K}), \mathrm{Q}$ is the ion activity product, $\mathrm{K}_{\mathrm{g}}$ is the pseudo-equilibrium constant (solubility constant) for the ratecontrolling reaction and $\sigma$ is the Temkin coefficient/rate of decomposition of the activated complex (assumed to be unity 


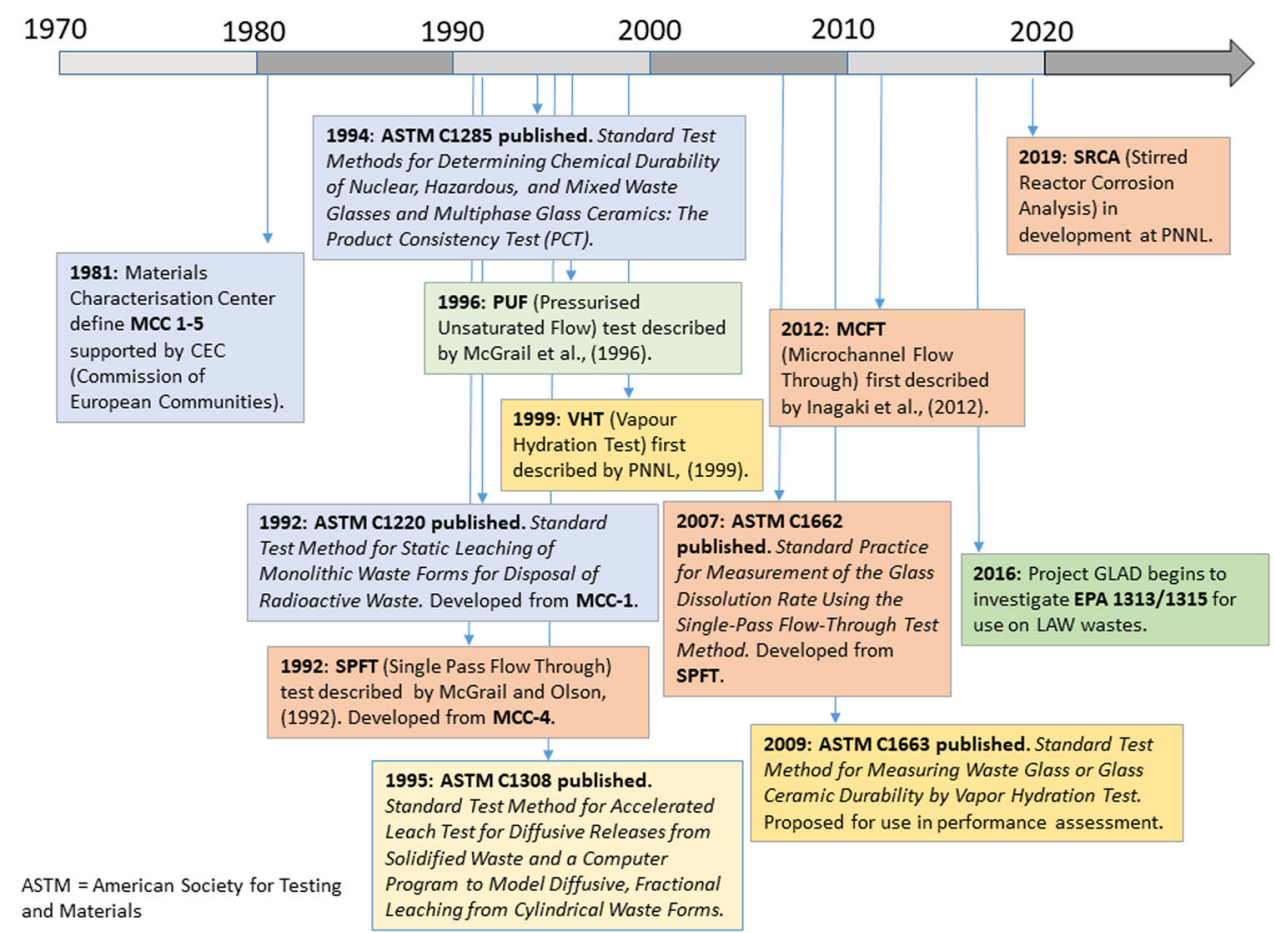

Fig. 3 Timeline showing the development and acceptance of the most commonly used glass durability tests. Colours highlight tests that are historically linked; blue: static tests derived from original MCC tests, pink: series of tests that aim to measure the forward rate, orange: tests using vapour. Other colours relate to stand-alone tests that were either developed for another purpose (i.e., not for general application to glass) or imported from another regulatory framework.

for borosilicate glass). As long as the lack of solution feedback is verified, the rate may be considered the forward rate $\left(r_{0}\right)$. To measure the forward rate, experiments maintain a constant $\mathrm{pH}$ and temperature and dilute conditions are achieved using fast flow rates, large solution volumes, low surface areas, or very short timescales. The forward rate is extrapolated to when the ion activity product $(Q)$ is equal to 0 . When $Q$ is equal to 0 the saturation state of the solution (described by the terms in square brackets in Eq. (1)) is equal to unity. To fit the remaining parameters in Eq. (1), the normalised dissolution rate of elements (requiring accurate determination of elemental fractions in the unreacted glass) is calculated across a range of temperatures and $\mathrm{pH}$. Multivariate linear regression is performed to simultaneously determine the values of $E_{a,} \eta$ and $\log k_{0}^{58-60}$. Note that the sign for the activity of $\mathrm{H}^{+}$can be negative under alkaline conditions pointing the fact that $\mathrm{OH}^{-}$rather that $\mathrm{H}^{+}$is the dominant active species and leading to the $\mathrm{V}$-shaped or U-shaped dependence typical of nuclear waste glass compositions ${ }^{30}$.

Equation (1), used to calculate the forward rate of reaction, can be considered incomplete as it does not include a term accounting for ion exchange and therefore does not represent that period where glass dissolution is incongruent ${ }^{29,30}$. Dissolution is usually incongruent for a short period of time, with some network modifiers participating in rapid ion exchange with $\mathrm{H}^{+}$/ $\mathrm{H}_{3} \mathrm{O}^{+}$. Once the immediate surface becomes depleted in exchangeable elements (e.g., $\mathrm{Na}, \mathrm{K}, \mathrm{Li}$ ), breakdown of the silicate network becomes the rate-limiting process. Thus, the forward rate regime is often identified by an equal normalised release of $\mathrm{Si}$ or $\mathrm{B}$ into solution, indicating congruent breakdown of the silicate network without $\mathrm{Si}$ incorporation into the alteration layer. In flow systems, dilution is often reported as $\log _{10}(q / S)$, where $q$ is the solution flow rate and $S$ is the surface area of the sample. The forward rate is measured when subsequent increases in $q / S$ do not affect the glass dissolution rate. In agitated solutions, the lack of solution feedback must be verified by aqueous chemistry measurements, sample surface analysis, and rigorous validation of the kinetic parameters $\left(E_{a}, k_{0}\right.$ and $\eta$ ) with those derived from other tests. The activation energy expected for breaking of $\mathrm{Si}-\mathrm{O}$ bonds in silicate, borosilicate and natural glasses ranges from 50 to $90 \mathrm{~kJ} \mathrm{~mol}^{-1}$ and is dependent on solution chemistry, $\mathrm{pH}$ and glass composition ${ }^{59,61-64}$.

The original MCC-4 protocol was a continuously flowing method applied to monolith samples, developed for use under constrained conditions with reference flow rates of $0.1,0.01$ and $0.001 \mathrm{ml} \mathrm{min}^{-1}$, reference temperatures of 40,70 and $90^{\circ} \mathrm{C}$ and three reference solutions. The MCC- 4 method was not widely used; however, the apparatus and protocol were adapted to form the basis of the Single Pass Flow Through (SPFT) method, first described by PNNL in $1992^{65}$ and later accepted as ASTM C1662 (Standard Practice for Measurement of the Glass Dissolution Rate Using the Single-Pass Flow-Through Test Method) in 2007. The microchannel flow-through (MCFT), like the SPFT, uses a high solution flow rate to avoid solution feedback, but is applied to monolith samples while allowing simultaneous observation of the 'depth' of corrosion. An alternative stirred method developed to determine forward rate kinetic parameters is the stirred reactor coupon analysis (SRCA), which relies upon constant agitation of solution under low SA/V ratio where solution feedback reactions are limited.

The Single Pass Flow Through (SPFT) test method, described by McGrail and Olson ${ }^{65}$, McGrail and Peeler ${ }^{66}$ and ASTM C1662 ${ }^{67}$, comprises a flow cell where the buffered input solution is continuously passed over a powder or monolith sample at a rate that prevents saturation but allows accurate detection of elements (Fig. 4a). Solutions are either ASTM type 1 water/ultra high-quality water (UHQ) (ultra-pure water with a specific resistance of 18.2 $\mathrm{M} \Omega$ ) or solutions made from UHQ water and analytical grade chemicals. The method is used to measure the forward rate of reaction by maintaining undersaturated conditions.

The SPFT method has reliably provided kinetic parameters for many simulant radioactive waste glass compositions ${ }^{59,66,68-71}$. The method requires that the limit of elemental detection of analytical 


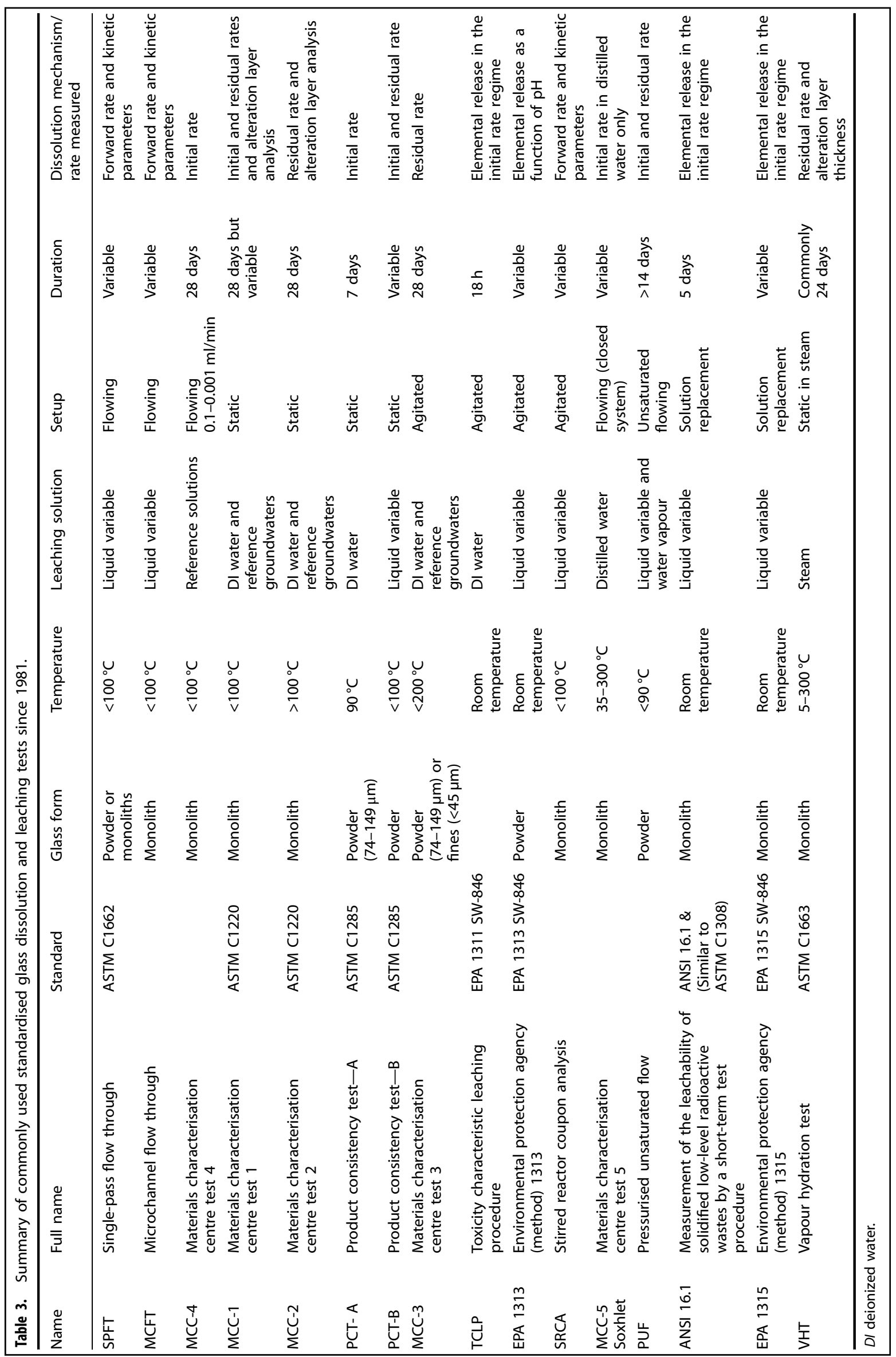


a

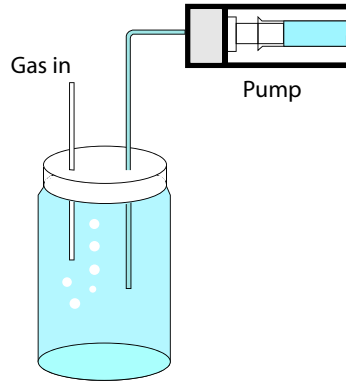

Input solution

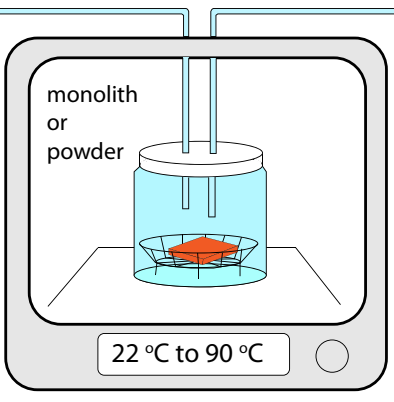

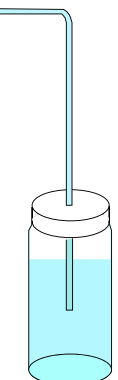

Output solution

b

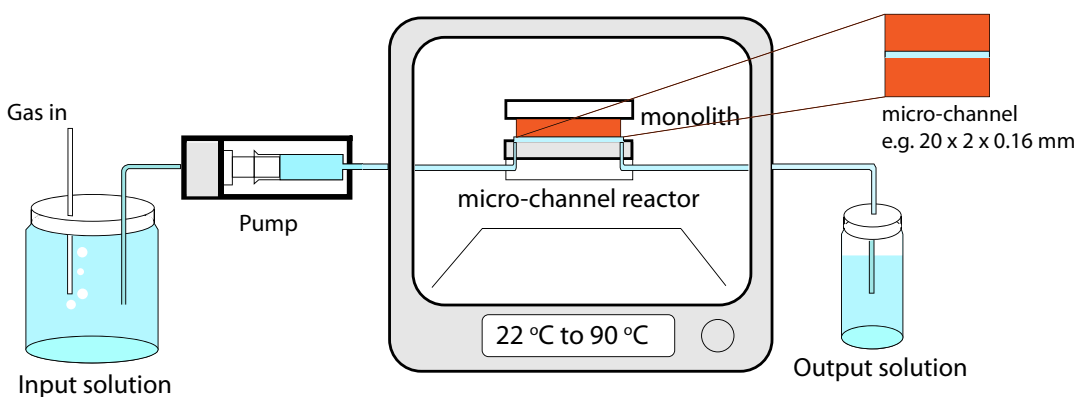

C

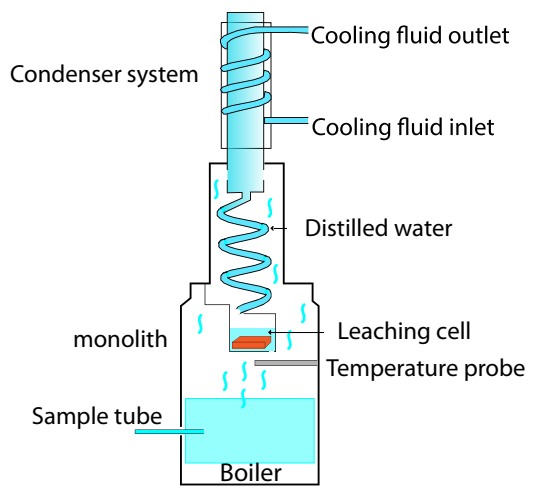

d

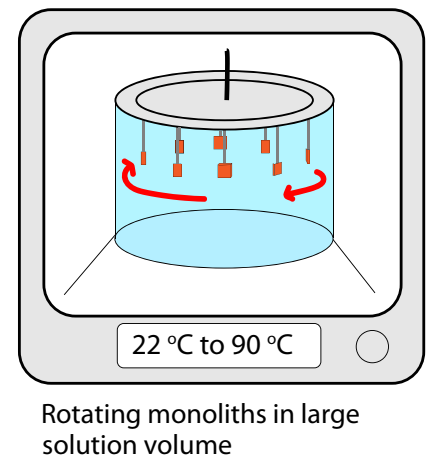

Fig. 4 Diagrams of methods measuring glass dissolution under dilute conditions. a Set-up of a SPFT method. b Set-up of a MCFT method. c Set-up of a Soxhlet method. d Set-up of a SRCA method.

equipment (e.g., Inductively Coupled Plasma (ICP) Optical Emissions Spectrometry or ICP Mass Spectrometry) be low, which can restrict the flow rate and, therefore, the extent of dilution that can be practically investigated. Depending on the nature of the material used, the existence of fine particles, which can either dissolve rapidly or become mobilised to block solution in-flow or out-flow ports, can hinder accurate determination of glass durability. A change in reactive surface area during the experiment is inevitable when performing experiments under flow conditions for long time periods, and this change can be especially pronounced under aggressive conditions with crushed powders, for example, under extremes of solution $\mathrm{pH}$ and at high temperature. To account for this a post-dissolution surface area correction was developed based on a shrinking core model that uses the mass of glass at the experiment endpoint and assumes spherical particle geometry for powder samples. This can be applied to determine the mass of glass at each sampling interval $\left.\right|^{57,59,71,72}$ and thus generate accurate glass dissolution data.

Despite using the shrinking core model, the SPFT method may not be always capable of yielding steady-state forward rate conditions over long time periods, and the rate of elemental release tends to decline under more aggressive conditions ${ }^{71}$. This is likely due to the difficulty in setting high enough flow rates to avoid gel layer formation and/or a significant reduction in reactive surface area over time. Altered gel layers have been observed in experiments with flow rates in excess of $200 \mathrm{~mL} \mathrm{~d}^{-1}$ (J. Icenhower, Personal Communication, March 29, 2021), which is significant if elements are released congruently because this suggests that some precipitate in a saturated boundary layer as per the hypothesis of Geisler et al. ${ }^{42}$ and Hellmann et al. ${ }^{73}$. Hence, the presence of an altered gel layer may, in some instances, be permissible during dissolution at the initial rate. It should be noted that glass-alteration layer formation cannot be strictly avoided in the SPFT methodology as there will always be some feedback effect-infinitely dilute conditions can never be maintainedthere will always be some silica in solution ${ }^{67}$. Recent supporting evidence is also provided by real-time in situ observations of silicate glass corrosion in which a $25-\mu \mathrm{m}$ thick alteration layer developed without any impact on the measured initial dissolution rate $^{74}$. Furthermore, gel layers were observed on the ISG in stirred coupon dissolution tests, which are hypothesised to allow the most dilute conditions with a SA $/ \sim 0.1 \mathrm{~m}^{-1}$. 
Practically, the SPFT test is a labour-intensive process requiring many months of constant operation and the analytical analysis of leachate from a large number of samples (e.g., in excess of 1000 in the studies by Backhouse et al. ${ }^{71}$ and Fisher et al. ${ }^{75}$. A recent assessment of SPFT data by Vienna et al. ${ }^{60}$ concluded that, when accounting for uncertainty in model parameter fitting, there was no statistically significant difference between model parameters for previously tested alkali-borosilicate glasses as long the fraction of tetrahedral boron $\left[f\left({ }^{[4]} \mathrm{B}\right)\right]$ was greater than a threshold value of 0.22 .

The microchannel flow-through (MCFT) test method, first described by Inagaki et al. ${ }^{58}$ as a monolith-only alternative to the SPFT, aimed to improve on the SPFT by minimising some of the uncertainties related to reactive surface area ${ }^{26,61}$. A small volume of solution is passed over the surface of a highly polished monolithic glass coupon through a 'microchannel' that ensures a known area of sample is in contact with the solution (Fig. 4b). In addition to solution chemistry, this method allows quantification of the forward glass dissolution rate by measuring the extent of surface retreat on the solid using surface roughness analysis techniques, for example, vertical scanning interferometry (VSI) or similar. Like the SPFT, this method ensures unsaturated solution contacts the glass surface and can be used to provide kinetic parameters relating to the forward rate of reaction.

Despite the short $(20 \times 2 \times 1.6 \mathrm{~mm})$ channel, the solution volume is small enough that a high SA/V ratio is achieved and it is possible that appreciable saturation can occur between the inlet and the outlet side of the sample. This assessment is supported by the observation that alteration depth is highest near the inlet port and decreases near the outlet port. Due to the fast flow rates, there is also the potential for some physical erosion to occur within the channel.

The Soxhlet test method, formally known as the Materials Characterisation Centre test 5 (MCC-5), was used by British Nuclear Fuels during the development of UK vitrified high HLW with similar protocols used in other countries including France and the USA. With the notable exception of facilities with large library of historical data available for comparison, such as Sellafield Ltd UK, the Soxhlet test has fallen out of use due to its complex and impractical set-up, which includes the use of borosilicate glass apparatus. The Soxhlet test method comprises a $\sim 40 \mathrm{ml}$ 'Soxhlet compartment' containing a glass monolith, a round-bottomed flask and reflux apparatus (Fig. 4c). Deionized (DI) water is heated until it condenses in the reflux apparatus and gradually fills the Soxhlet compartment. Water is periodically removed from the compartment via a siphon back into the flask, thus simulating a flow environment where the sample is continually exposed to fresh solution every $\sim 15 \mathrm{~min}$. Tests are usually performed for 28 days with the mass loss of the monolith and the composition of the leachate used to determine bulk and elemental dissolution rates respectively under dilute conditions. The leaching of elements from the borosilicate glass apparatus can be accounted for to some extent by running blanks in the absence of a glass specimen.

This test uses a low SA/V and high temperatures $\left(\sim 100^{\circ} \mathrm{C}\right)$. Due to the reflux method employed, the Soxhlet method does not have the potential to be adapted for a wide range of solution compositions (e.g., simulant groundwater containing salts), although the temperature can be varied by altering conditions in the condenser set-up.

The Soxhlet method is intended to provide initial dissolution rate data and has been used, in the past, to estimate dissolution reaction activation energy values ${ }^{76}$. However, the presence of alteration layers observed on some samples indicate that the solutions were not always dilute and, therefore, may not always have measured the forward rate. Moreover, the lack of $\mathrm{pH}$ control in the system means that Soxhlet tests have been superseded by the SPFT and MCFT methods, which apply pH buffers for this purpose. Furthermore, the unavoidable interference in $\mathrm{B}, \mathrm{Si}$ and $\mathrm{Na}$ dissolved from the borosilicate apparatus means that the Soxhlet is not ideal for determining accurate forward rates but can reliably measure the initial rate regime.

As SPFT and MCFT are complex and time consuming, alternative methods are, at the time of writing, under evaluation to assess their ability to rapidly quantify the forward dissolution rate using a range of glass compositions. The SRCA method involves the suspension of multiple glass coupons in a sealed steel reactor vessel containing a large volume of solution with SA/V in the order of $0.1 \mathrm{~m}^{-1}$. The solution is stirred constantly using an impeller, thus avoiding localised saturation at the surface of the glass coupons and preventing gel layer formation (Fig. 4d). Challenges associated with solution analysis at near-detection concentrations are circumvented by measuring the step height with respect to a partially masked surface, for example using atomic force microscopy, VSI or optical profilometry to determine coupon volume loss $^{77}$. Thus, SRCA could become an alternative method for obtaining kinetic parameters under ultra-dilute conditions over short timescales.

\section{Glass durability under static non-dilute conditions}

Glass durability test methods using under non-dilute conditions where the same solution is used throughout are typically termed static methods. Static methods are often the most commonly employed methods to investigate glass durability because they are easy to set up and relatively low maintenance compared to other method types. The product consistency test (PCT), accepted as ASTM C1285 Standard Test Methods for Determining Chemical Durability of Nuclear, Hazardous, and Mixed Waste Glasses and Multiphase Glass Ceramics: The Product Consistency Test $(P C T)^{78}$, is the most common static method used to determine elemental release rates from powdered vitrified materials. The PCT-A method was developed specifically to rapidly assess durability relative to other glasses and has undergone extensive precision and bias analysis ${ }^{79}$.

The MCC -1 method, applied to monoliths, is another commonly used static durability method, which was first accepted as ASTM C1220: Standard Test Method for Static Leaching of Monolithic Waste Forms for Disposal of Radioactive Waste in $1992^{80}$. The MCC2 is a static leach test on monolithic samples using standard leaching solutions at increased temperatures of 110, 150 and $190^{\circ} \mathrm{C}$. MCC-1 and MCC-2 have a much lower surface area to volume ratio than tests using powder and allow post-test alteration layers to be analysed.

The Product Consistency Test (PCT-A and PCT-B) standard methods (described in ASTM $\mathrm{C} 1285^{78}$ ) were developed as a rapid quality check of glass durability during production ${ }^{81}$. In general, glass is crushed to a specific size fraction allowing an estimate of surface area to be made when combined with the known density of the glass, washed to remove fine particles, and incubated at a known glass SA/V ratio in stainless steel, Perfluoroalkoxy (PFA), or polytetrafluoroethylene (PTFE) pots at temperatures of up to $90^{\circ} \mathrm{C}$ (Fig. 5a). The PCT method is primarily used to determine the residual rate of glass dissolution, with the tightly constrained PCTA method comprising a 7-day test in UHQ water at $90^{\circ} \mathrm{C}$ with a SA/V of $2000 \mathrm{~m}^{-1}$. In contrast, the PCT-B protocol allows greater flexibility in the conditions of the method, such that any solution, $\mathrm{SA} / \mathrm{V}$ ratio, temperature, timescale, solution composition and atmosphere can be varied.

If glass preparation and powder washing protocols are adhered to, the PCT is simple and reproducible ${ }^{79,82}$. Also, due to the low risk of leakage, static leach tests can easily be adapted for use with radioactive samples confined to hot cells, unlike flow through or agitated tests. Many non-standardised static tests deviate slightly in test duration, SA/V ratio or solution chemistry 
a ASTM- C 1285 (PCT- A/B)

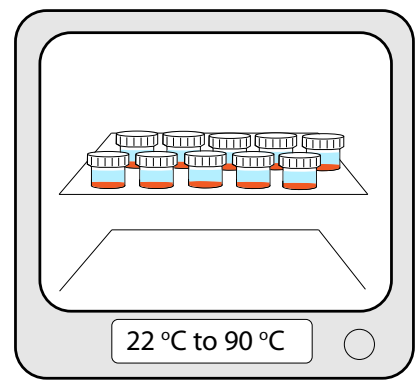

b Static monolith dissolution tests Example-ASTM C1220 (MCC-1)

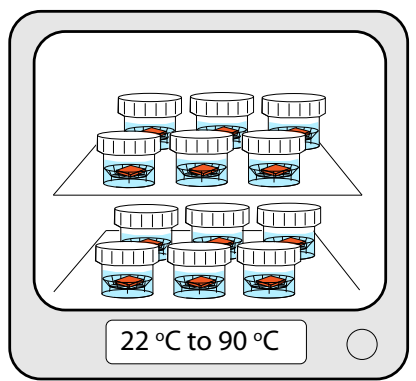

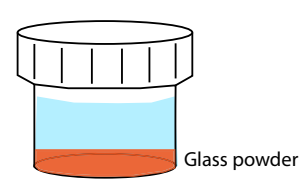

C Adaptation with controlled atmosphere
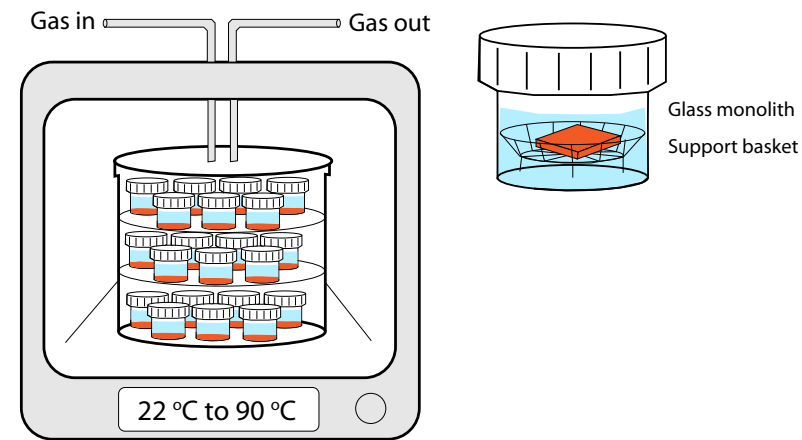

Fig. 5 Diagrams of methods measuring glass dissolution under non-dilute static conditions. a Set-up of a static powder dissolution test like the PCT method. b Set-up of a static monolith dissolution tests like the MCC-1 method. c A method for conducting both types of test under a controlled atmosphere.

but may be similar enough for normalised results to be compared with PCT-B results ${ }^{83}$.

Unless a dissolution vessel with a broad base is used to spread the glass particles out in a single layer, they have a tendency to coalesce such that the lower layers of glass are no longer exposed to the bulk solution and localised super-saturation may occur. In a similar vein, aggregation of glass powders at longer timescales, either facilitated through the leachant (particularly aqueous $\left.\mathrm{CaOH}_{2}\right)^{84,85}$ or due to the precipitation of secondary minerals from poorly durable glasses, can also introduce significant uncertainty. Thus, it is often the case that residual rates measured by the PCT method are underestimated since the exposed reactive surface area is lower than the estimated surface area. The PCT method uses glass powder, therefore is susceptible to errors in calculating the initial surface area. Changes in the SA/V ratio can also occur over long timescales due to loss of water by evaporation (ASTM C1285 states that for both PCT-A and PCT-B any samples with $>5 \%$ solution loss should be discarded). Calculating the residual rate from PCT tests, especially over longer time periods, can be challenging as rates are extremely slow, and continually decreasing. The changes in the elemental release are very small and may be lost amid analytical uncertainties resulting from detection limits and changing SA/V.

The PCT test method is intended to be sacrificial, meaning the samples are discarded at each time point solution chemistry from replicate samples is measured. Even the relatively small mass of glass $(30-100 \mathrm{~g})$ required to conduct a PCT test is time consuming to prepare, but a sacrificial approach does have the advantage that glass powder can be analysed at each time point (e.g., by scanning electron microscopy (SEM), X-ray diffraction (XRD), time of flight-secondary ion microscopy (ToF-SIMS) to understand secondary phase formation can occur. The main value of PCT-A is its ability to quickly rank the relative durability of multiple glasses whilst PCT-B can be used to study longerterm effects including the formation of secondary phases if run over a long enough time period.
In the Materials Characterisation Centre-1 (MCC-1) standard methodology (ASTM $\left(1220^{80}\right.$ ), a polished coupon of glass, with a recommended surface area of $400 \mathrm{~mm}^{2}$, is contacted with solution for a fixed time period and at a fixed temperature. A sample holder/basket ensures that the entire surface of the monolith is always in contact with solution (Fig. 5b). The SA/V ratio (recommended to be $10 \mathrm{~m}^{-1}$ ) is lower using glass coupons when compared to the standard PCT-A with powders (recommended to be $2000 \mathrm{~m}^{-1}$ ), therefore the reaction progress is slower. In common with the PCT-A/B, the MCC-1 test is sacrificial in nature meaning that samples are discarded at each timepoint and that a great number of identical monoliths must be prepared to cover the time points required. However, post-reaction samples can be sectioned for alteration layer analysis by a range of solid-state characterisation and imaging techniques (e.g., SEM, XRD, ToFSIMS). Reducing the SA/V ratio under static conditions increases the alteration layer thickness by maintaining undersaturated conditions and therefore the initial rate of glass dissolution over a longer time frame 86,87 .

Coupon preparation is a relatively slow and labour-intensive process and the rate-limiting factor in performing MCC-1 tests. The recommended surface area means that coupons, most commonly of dimensions $10 \times 10 \times 4 \mathrm{~mm}$, are first cut by diamond saw to the required size and then ground and polished to the required finish. The lower SA/ $V$ ratio results in a long time to reach saturation and to determine a residual rate compared to static methods that use powdered material. Overall, the MCC-1 provides normalised elemental mass loss data for samples under lower SA/ $V$ ratio conditions than both $P C T$ tests and reacted surfaces can be more easily prepared for analysis.

\section{Glass durability under static non-dilute conditions in steam} The Vapour Hydration Test (VHT) standard method uses high temperatures and water vapour (steam) to accelerate glass alteration. It was first published by PNNL in 1999 and accepted in 2009 as ASTM C1663 Standard Test Method for Measuring Waste 
a

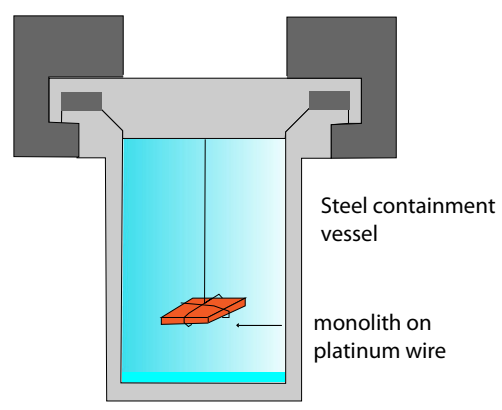

b

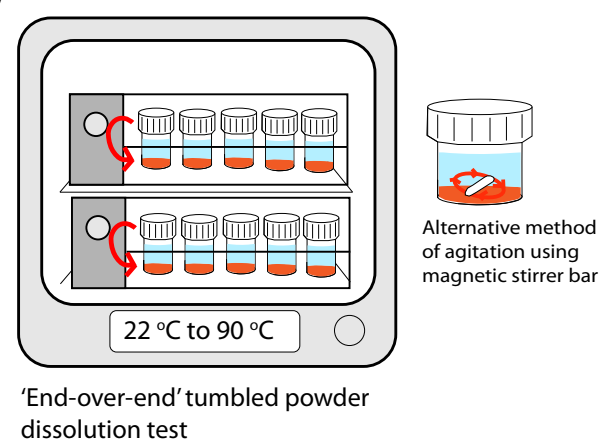

Time interval $1 \quad$ Time interval 2

C

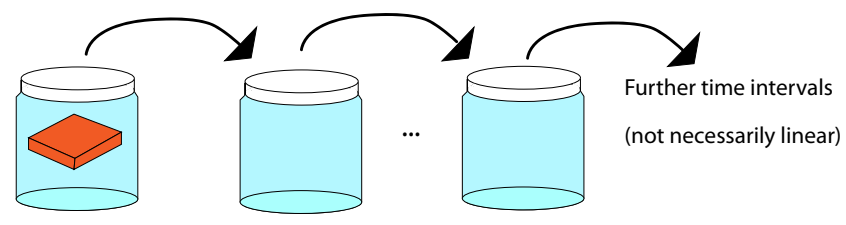

Monolith transfered to fresh leaching fluid at set intervals

d

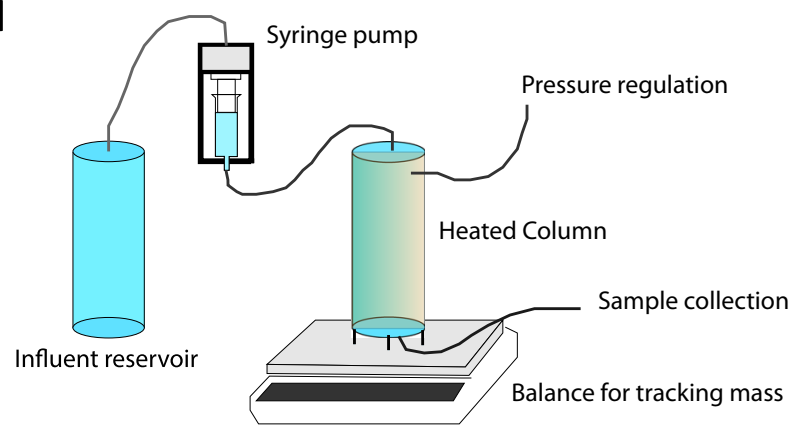

Fig. 6 Diagrams of methods measuring glass dissolution under non-dilute conditions in steam, in agitated, semi-dynamic and dynamic conditions. a Set-up of the VHT method. b Set-up of an agitated test like the EPA 1313 method. c Set-up of fluid replacement tests like the ANS.16.1, ASTM C1308 and EPA 1315 methods. d Set-up of the PUF method.

Glass or Glass Ceramic Durability by Vapour Hydration Test ${ }^{88,89}$. An almost identical method ${ }^{90-92}$ controls the relative humidity within the experimental system using a saline solution and allows a VHT-like test to be performed at lower temperatures representing dissolution by water vapour rather than liquid water. In the ASTM C1663 VHT method polished glass coupons (medium polish 30 micron) are suspended by a platinum wire holder in a sealed stainless steel containment vessel, which is then subjected to temperatures of up to $200{ }^{\circ} \mathrm{C}$ for a standard duration of 28 days though shorter or longer durations are possible (Fig. 6a). Since the dissolution of elements from the glass is limited to a surficial water film, the formation of a silica gel layer and secondary precipitates is rapid. The post-reaction coupons are sectioned and imaged (typically using scanning electron microscopy) so that the thickness of the corrosion layer can be quantified. The thickness is then directly used as a measure of the extent of glass dissolution to calculate the rate of mass loss over the duration of the experiment.

The VHT is an accelerated test method that may provide useful insight to the nature of expected secondary phases during dissolution (albeit biased towards high-temperature hydrothermal phases). However, since it is performed at temperatures that are unrepresentative of true disposal conditions, it is difficult to justify its use as a predictive tool for vitrified radioactive waste disposal.
It could be argued that VHT tests may represent a scenario where soluble phases are precipitated by alteration vapour that would otherwise quickly dissolve in water. Moreover, the VHT method shows poor reproducibility between laboratories, operators, and even the same operator on different occasions, and it also exhibits high variability in the quantified dissolution rate due to the subjective nature of measuring the alteration layer thickness (typically on the order of $\mu \mathrm{m}$ ). This inconsistency results in large uncertainties in the dissolution rate, nevertheless, it is currently used to qualify LAW glasses for disposal in the US ${ }^{16}$.

In an attempt to replicate potential repository corrosion scenarios where one school of thought suggests that vitrified HLW in a geological repository may initially come into contact with water vapour before encountering groundwater solution in the fully aqueous phase ${ }^{93}$, hybrid VHT-MCC-1 like tests have been conducted $^{56,94-97}$. As such, glass vapour hydration corrosion is likely to dominate for a period of time leading to the development of secondary alteration phases, which may impact the later dissolution process. Literature suggests that pre-vapour corroded nuclear waste glass may be detrimental to the durability in subsequent static aqueous solution dissolution when compared with glass that was not pre-vapour corroded ${ }^{94}$. Such results were attributed, in part, to the dissolution and instantaneous release of elements from the secondary phases that formed in the vapour 
stage, which raised the $\mathrm{pH}$ of the surrounding solution, thus increasing the rate of dissolution, as evidenced from studies of SON68 ${ }^{94}$. Such hybrid tests are not standardised; therefore, authors have conducted them under various conditions (e.g., relative humidity, temperatures, aqueous dissolution media). The key aspect of such a methodology may be the potential to demonstrate the free release/more effective release of radioactive elements incorporated in the secondary phases from vapour corrosion, which may subsequently readily dissolve during the aqueous dissolutions stage. Future efforts to constrain such hybrid tests will be beneficial to the safety case for geological disposal.

\section{Glass durability under agitated non-dilute conditions}

Agitated tests give consistently higher rates of elemental release than static tests performed under similar conditions (see section 'Determination of International Simple Glass initial and residual dissolution rates'). This is likely due to solution agitation preventing the build-up of a water diffusion boundary layer that can affect localised solution saturation in static tests. In addition, agitation might result in particle-particle collisions and expose fresh surfaces for leaching, even in hard materials like glass. The methods listed below all employ sample agitation to induce measurable elemental release over a short time period.

The Materials Characterisation Centre-3 (MCC-3) standard method $^{54}$ is a high temperature, agitated test that is applied to glass powder, which was developed to leach elements into solution in a closed system. As with the original MCC-1 and 2 methods, temperatures of $40,90,110,150$ and $190^{\circ} \mathrm{C}$ and the use of reference solutions are specified, along with vessel rotation of 10-14 cycles/min by end-over-end tumbling. The aim of this test is to accelerate glass dissolution to generate saturated solution conditions rapidly. This method has fallen out of common usage, most likely due to the availability of static tests that provide similar information (e.g., PCT method) but without the limitation of damaging particles in glass on glass collisions, which can affect the total surface area and hinder preservation of secondary phases. The PCT test adopted the particle size recommendations of the MCC-3 but omitted the higher temperature range and endover-end tumbling to give a static powder leach test.

The Environmental Protection Agency 1313 (EPA 1313) standard method $^{98}$ is a room temperature agitated batch-leaching protocol, developed in the US Environmental Protection Agencies Leaching Environmental Assessment Framework (LEAF) SW-864 methods that measures liquid-solid partitioning as a function of $\mathrm{pH}$ (Fig. 6b). The EPA 1313 method was originally intended for use on solid waste materials, including sediments, sludges, construction materials and mining wastes, and has recently been adapted for use with low-activity, non-heat producing simulant radioactive waste alkali-borosilicate glasses ${ }^{99}$. Nine end-of-test $\mathrm{pH}$ points between 2 and 13 are set by the addition of known amounts of nitric acid $\left(\mathrm{HNO}_{3}\right)$ or potassium hydroxide $(\mathrm{KOH})$ to $\mathrm{UHQ}$ water in vessels containing size-reduced glass powder at a solid to liquid ratio of 1:10 (mass:mass). The vessels are agitated by end-over-end tumbling, at room temperature for a specified time (typically $24 \mathrm{~h}$ ) before the solution is removed for aqueous chemical analysis. Release of constituents of concern per gram of solid are provided across the range of $\mathrm{pH}$ values enabling different materials to be compared to one another.

An interlaboratory validation exercise conducted to investigate the application of the EPA 1313 method for use on glass found high reproducibility. During this exercise, the method was optimised for application to vitrified material, by (i) reducing the sample size from the $20 \mathrm{~g}$ specified in the EPA 1313 method down to $1 \mathrm{~g}$ (a large sample size is not required for homogeneous glass); (ii) using two sieves to select a specific size fraction of 75-150 $\mu \mathrm{m}$ for SA/V determination and (iii) addition of a washing procedure to remove glass fines. These last steps bring the glass preparation steps in line with those described in the PCT test methodology.

The strategy for setting the end-of-test solution $\mathrm{pH}$ does not ensure that the $\mathrm{pH}$ is constant for the duration of the experiment. This is particularly the case at target $\mathrm{pH}$ values below $\mathrm{pH} \mathrm{5}$, where glass exchanges ions rapidly, resulting in a rapid $\mathrm{pH}$ increase. A pre-test titration can be used to estimate the amount of acid needed to achieve a target $\mathrm{pH}$ after a set time; however, acid additions would be required throughout the experiment duration (e.g., using an auto-titrator) to maintain the desired $\mathrm{pH}$ value. In its current form, this test is used to provide a value for element leached as a function of $\mathrm{pH}$, however, investigations are underway to ascertain if it is possible to obtain dissolution rate data and to what extent this method maintains dilute conditions.

For toxic elements (e.g., $\mathrm{Pb}, \mathrm{Cr}, \mathrm{Ba}, \mathrm{Cd}$, etc.) contained in nuclear waste glasses, the US regulatory framework also specifies an Environmental Protection Agency test Toxicity Characteristic Leaching Procedure (TCLP-SW-846 Method 1311) ${ }^{100}$. The TCLP was designed to simulate leaching under conditions of co-disposal in a municipal solid waste landfill. It measures the mobility of both organic and inorganic analytes present in liquid, solid, and multiphasic wastes. Samples of recommended particle size fraction of $<9.5 \mathrm{~mm}$ (reduced to $<1 \mathrm{~mm}$ for glass) are immersed in deionised water in an extraction vessel that is rotated, end over end, at $30 \pm 2 \mathrm{rpm}$ for $18 \pm 2 \mathrm{~h}$ at room temperature, defined as $23 \pm 2{ }^{\circ} \mathrm{C}$. The solution chemistry is then measured once at the end of the extraction period. There are additional procedures specified for recapturing and analysing volatiles released during the TCLP procedure and the release of headspace gas build-up, however, these are not measured for glass samples as they are assumed to have been destroyed during the melting process. The TCLP procedure is not intended to produce a release rate, but rather a release value that can be compared with other samples tested under the same conditions or to an acceptability limit.

\section{Glass durability under semi-dynamic non-dilute conditions}

Semi-dynamic tests include those that use solution replacement to accelerate the diffusive release of elements in order to simulate waste form behaviour over long timescales at low temperatures. A number of very similar tests exist, developed by different recognised bodies, based on an original leaching test proposed by the IAEA ${ }^{53}$. The ANS 16.1 method, Measurement of the Leachability of Solidified Low-Level Radioactive Wastes by a Short-Term Test Procedure, was first published in $1986^{101}$ adapted from the IAEA ${ }^{53}$ and ISO 6961:1982(E) ${ }^{102}$. The ANS 16.1 method was further adapted to become ASTM C1308 (Standard Test Method for Accelerated Leach Test for Diffusive Releases from Solidified Waste and a Computer Program to Model Diffusive, Fractional Leaching from Cylindrical Waste Forms) that was approved in 1995. Most recently the Environmental Protection Agency method 1315 from the SW-846 methods has been adapted for use on glass waste forms ${ }^{103}$. Each of these tests are designed to measure diffusive release of elements from monolith samples during multiple solution replacement stages (Fig. 6c). It is impossible, when considering glass dissolution, to separate the processes of ion exchange and hydrolysis so these tests can only be said with certainty to represent early-stage glass dissolution in dilute solution.

The American National Standards Institute method 16.1 (ANS 16.1) 2019 edition is an adaptation of the original 1986 procedure modified for use on radioactive materials ${ }^{101}$. The procedure states that it is specifically a short-term test to assess the 'release rates of non-volatile radionuclides from low-level radioactive waste forms in demineralised water over a test period'. The procedure cautions that the test is not designed to represent waste form behaviour in a specific disposal environment and that results cannot be used to predict waste form performance. The purpose of the test is to 
provide results, under specified test conditions, that can be used to compare one waste form to another in the form of a leachability index (LI). The leachability index is defined by Eq. (2):

$L_{i}=\log \left(\frac{\beta}{D_{e, i}}\right)$

where $L_{i}$ is the leachability index of element $i$ (unitless), $\beta$ is a defined constant $\left(1.0 \mathrm{~cm}^{-2} \mathrm{~s}^{-1}\right)$ and $D_{\mathrm{e}, \mathrm{i}}$ is the effective diffusivity of element $i$ calculated from the test data $\left(\mathrm{cm}^{-2} \mathrm{~s}^{-1}\right)^{101}$.

ANS 16.1 is designed for any material from which monoliths can be formed. Monoliths, preferably of cylindrical geometry, are immersed in the solution and removed every $24 \mathrm{~h}$ to be immersed in fresh solution. The concentration of the elements in question are measured after each exchange of solution. The sample should also be rinsed between each immersion and the rinse solution also analysed. Leaching vessels need to be resistant to chemical damage and adsorption of elements from the waste samples (e.g., high-density polyethylene (HDPE) or polyvinyl chloride (PVC). However, they do not necessarily need to be heat resistant for this method as it is performed at room temperature (defined as between 18 and $28^{\circ} \mathrm{C}$. The ANS 16.1 was designed to be quick, lasting just five days unless additional time points are added, and easy to perform, with solution replacement at regular intervals of $24 \mathrm{~h}$ such that this test can be performed within a working week. This test is limited by the detection limits of aqueous phase analysis; elemental release from highly durable materials, like borosilicate glass, are very low at room temperature over $24 \mathrm{~h}$ timescales. Nevertheless, this test has been performed successfully on a variety of glasses and ceramics ${ }^{23,104}$.

The standard test method for accelerated leach test for diffusive releases from solidified waste and a computer program to model diffusive fractional leaching from cylindrical waste forms (ASTM C1308) ${ }^{105}$ is a modification of other semi-dynamic tests such as the IAEA test set out in Hespe et al..$^{53}$ and the ANS 16.1 Leach test. As with the ANS 16.1, monolithic samples are immersed in solution at a surface area to volume ratio sufficient to allow both complete immersion and element detection. The solution is completely replaced at set time intervals of 2, 7, 17 and $25 \mathrm{~h}$ and then every $24 \mathrm{~h}$ for 10 days with the concentration of elements of interest measured after each exchange. Building on the ANS 16.1 , intended to produce data quickly for comparison purposes, the ASTM C1308 uses a computer programme to fit the experimental results with a mechanistic diffusion model. Like the ANS 16.1, a single test temperature can be used to compare the diffusive release of different materials. In addition, tests can be performed over a range of temperatures allowing the model to extrapolate elemental release over long time periods provided that the results of tests conducted at elevated temperatures are comparable to results at the reference temperature of $20^{\circ} \mathrm{C}$ (e.g., they both fit the mass diffusion model and the diffusion coefficients show Arrhenius behaviour).

The computer programme uses a finite cylinder model to provide the value of the effective diffusion coefficient, the modelled incremental fraction leached, and the modelled cumulative fraction leached alongside a measure of the goodness of fit of the model ${ }^{105}$. This test had been widely applied to radioactive wastes most recently in the assessment of novel glass waste forms ${ }^{106-108}$.

The Environmental Protection Agency 1315 standard method (EPA 1315) was originally designed for application to any monolithic or compacted granular material. It is currently under evaluation by the authors for application to small rectangular glass coupons. In common with the ANS 16.1 and the ASTM C1308, it is a test designed to measure the diffusion-controlled release of elements from the sample. However, the EPA method differs in a number of ways. The main change, relevant to the use of this method on non-porous samples such as glass, is that nine fixed leaching intervals are specified with samples taken at $2 \mathrm{~h}, 1,2,7$, $14,28,42,49$ and 63 days. This measures release at 23-h intervals, 7- day intervals and 14-day intervals to show how solution saturation affects diffusive release (see Table 4). In most other aspects, the test procedure is identical to the ANS 16.1 and ASTM C1308. Results are plotted in terms of concentration of elements of concern at each interval, as a cumulative release and as mean interval flux.

\section{Glass durability under dynamic non-dilute conditions}

The Pressurised Unsaturated Flow (PUF) test method was developed to understand glass dissolution under disposal conditions representative of partial hydraulic saturation as expected for shallow subsurface burial in an arid environment (e.g., at the Hanford Site) ${ }^{109-111}$. The PUF test uses an open system with size-reduced material (e.g. $170-250 \mu \mathrm{m}$ ) packed into a column, which is heated to temperatures up to $90^{\circ} \mathrm{C}$ and subjected to water infiltration at a low flow rate. Gravity-assisted drainage is utilised, such that the water content is maintained at $\sim 20 \%$ or less ${ }^{110,112}$ (Fig. 6d). In-line monitoring of effluent chemistry, $\mathrm{pH}$ and electrical conductivity is performed and posttest solids are analysed for secondary alteration minerals and alteration layer thickness ${ }^{109}$. The high SA/V ratios utilised in this method result in rapid reaction rates and the formation of easily identifiable crystalline alteration phases. The test is complex and labour intensive, as it must be frequently monitored and manipulated to maintain hydraulically unsaturated conditions.

\section{EVALUATION OF ACCELERATED DURABILITY METHODS AND SOME COMMON ISSUES AND CHALLENGES}

As previously noted, while many of the standard test methods described above were developed with the purpose of rapidly screening different vitrified waste compositions, i.e., to compare the performance of different glasses relative to one another or to a glass standard, these methods are more commonly used today to infer long-term glass dissolution rates within disposal environments ${ }^{14,71,83,109}$. There are several factors that must be considered when translating the results acquired from accelerated glass corrosion methods to disposal conditions. Experiments must take into account differences in groundwater chemistry, atmosphere, temperature and any factors specific to the test procedure such as $\mathrm{pH}$ controls, sample preparation and agitation.

Table 4. Summary of the main differences between the three most commonly used solution replacement tests to measure diffusive leaching from monolithic waste samples.

\begin{tabular}{llll}
\hline Test & Solution replacement interval & Temperature & Solution \\
\hline ANS 16.1 & Intervals of $24 \mathrm{~h}$ for at least five days & $18-28^{\circ} \mathrm{C}$ & DI water \\
ASTM C1308 & $2,7,17$ and $25 \mathrm{~h}$ and daily for the next 10 days & $20^{\circ} \mathrm{C}$ and other temperatures as necessary & $\begin{array}{l}\text { DI water, synthetic or actual } \\
\text { groundwater }\end{array}$ \\
EPA 1315 & $\begin{array}{l}2 \mathrm{~h} \text {, followed by } 1,2,7,14,28,42,49 \text { and } \\
63 \text { days }\end{array}$ & $\begin{array}{l}20 \pm 2{ }^{\circ} \mathrm{C} \text {, and other temperatures as } \\
\text { necessary }\end{array}$ & $\begin{array}{l}\text { DI water, synthetic or actual } \\
\text { groundwater }\end{array}$ \\
\hline
\end{tabular}


The most common methods of accelerating glass corrosion, as described in the methods detailed in this review, are to (1) increase the temperature of the corrosion reaction, (2) modify the $\mathrm{pH}$ of the leaching medium (thus enhancing silica solubility) and (3) to increase the amount of reactive surface area exposed to a given amount of solution (the SA/V ratio). Many of the glass dissolution mechanisms described at the beginning of this review will be strongly influenced by these factors, which will, in turn, impact the magnitude of the quantified dissolution rate.

Temperatures within a shallow, near-surface $(<200 \mathrm{~m})$ disposal facility suitable for non-heat producing, lower-activity waste are expected in the range $10-20^{\circ} \mathrm{C}$. In deep geological disposal environments, temperatures are expected $>40^{\circ} \mathrm{C}$, due to a combination of increasing geothermal gradient with depth, and emplacement of heat-generating waste ${ }^{113}$. Temperatures of $>50^{\circ} \mathrm{C}$ (up to and above $90^{\circ} \mathrm{C}$ ) are expected in the thermal phase-the initial years in repositories with heat-generating waste -but will not be sustained over the repository lifetime as the radiogenic heat decreases with radioactive decay. Temperatures of $>50^{\circ} \mathrm{C}$ are often used in accelerated dissolution methods to gain meaningful results over more practical timescales, and $90^{\circ} \mathrm{C}$ is commonly used since it maintains leaching solutions below their boiling point whilst maximising the glass-alteration rate. Test methods that use temperatures in excess of this, e.g., the Soxhlet and VHT methods at 100 and $200{ }^{\circ} \mathrm{C}$, respectively, while allowing insight to secondary phase alteration, should be expected to significantly alter the nature of the dissolution reaction. It is preferable to conduct experiments under conditions close to the expected repository environment. However, with durable materials like glass, some degree of compromise is required. Most waste forms are expected to contact liquid water and therefore $90^{\circ} \mathrm{C}$ is often viewed as that compromise though the case has been made for initial steam/water-vapour driven corrosion of heat-generating high-level waste ${ }^{55}$.

The $\mathrm{pH}$ is another key control on the rate of glass dissolution with silicate glasses showing a typical ' $V$ ' or ' $U$ ' shaped dependence. Faster rates of dissolution are observed with both increased acidity, and increased alkalinity, with the lowest dissolution rates usually observed between $\mathrm{pH} 7$ and 9 but evolving with time and reaction progress $\mathrm{s}^{30,114}$. The rate-limiting step, in the case of silicate glasses, is the breakdown of $\mathrm{Si}-\mathrm{O} /$ $\mathrm{Si}-\mathrm{OH}$ bonds at the glass surface and this is enhanced by an increase in both $\mathrm{H}^{+} / \mathrm{H}_{3} \mathrm{O}^{+}$and $\mathrm{OH}^{-}$that can attack the $\mathrm{Si}-\mathrm{O}$ bond. The solubility of silica is little affected between $\mathrm{pH} 1$ and 9 but increases rapidly above $\mathrm{pH} 9$ further driving dissolution under alkaline conditions ${ }^{115}$. Tests aiming to obtain kinetic data, such as the SPFT, require that the $\mathrm{pH}$ is kept constant (see section ' $\mathrm{pH}$ buffers' on buffers). However, most tests are unbuffered and glass dissolution increases the $\mathrm{pH}$, via the release of alkaline elements and $\mathrm{OH}^{-}$, to a natural $\mathrm{pH}$ determined by the glass composition, temperature and solution volume. In disposal environments, the $\mathrm{pH}$ will be initially determined by the groundwater chemistry but may vary with time due to the evolution of the groundwater in contact with the waste form, the engineered barrier and construction materials.

Accelerated dissolution by increasing the ratio of glass surface area $(S A)$ to solution volume $(V)$ is utilised in many of the test methods described in this review. For example, the PCT-A method requires glass materials to be crushed and sieved to a 75-150- $\mu \mathrm{m}$ size fraction, and subsequently washed to remove fine particles adhered to the glass surface. The fines can rapidly dissolve and skew dissolution rate determination. Moreover, the surface area of the particles themselves can change (increase) during the dissolution reaction, resulting in an underestimation of the dissolution rate when normalised to the initial surface area. Numerous challenges are presented by this method of dissolution acceleration, not unique to glass materials, but also found in studies of other systems, for example, mineral weathering ${ }^{116}$.
Estimating, or even measuring accurately, the reactive surface area of crushed glass introduces a degree of uncertainty (and issue discussed in detail in section 'Specific surface area').

Finally, the use of UHQ water in accelerated dissolution tests represents a gross oversimplification of disposal environments, where multiple inorganic and organic species may be present. These species can influence the dissolution rate of vitrified material when naturally present in groundwater, or derived from the interaction of groundwater with other parts of the engineered barrier system of a disposal facility (e.g., cement ${ }^{117,118}$, clay ${ }^{119}$ or the metallic container ${ }^{120}$. Moreover, ultra-pure $18 \mathrm{M} \Omega \mathrm{cm}$ water is an extremely aggressive solvent, capable of dissolving elements rapidly from both the glass and the containment vessel. For this reason, to avoid contamination from dissolution vessels, highperformance polymers are generally used in preference to glass or stainless steel in laboratory testing. The use of UHQ is necessary for inter-lab comparability and as a solution in advance of sitespecific groundwater but its use will accelerate the early stages of glass dissolution.

Specific issues that are often encountered in the application of accelerated dissolution methods of vitrified materials, i.e., normalisation of the dissolution rate, measurement of surface roughness and surface area, sample polishing and sample washing, the use of buffers to maintain $\mathrm{pH}$, vessel material, issues with multiphase glasses and the effect of varying test timescale and test atmosphere, are described below.

\section{Normalisation of the dissolution rate}

In many of the accelerated dissolution methods described in this review, the dissolution rate of elements is quantified by normalising the concentration of the element released to solution to the fraction of that element in the glass and the SA/V ratio. By normalising the mass loss of each element to the mass fraction of each element in the glass, it is possible to compare the relative release of each element. The normalised dissolution rate for a particular element will only be as accurate as the method used to determine the mass fraction of that element in the unreacted glass with the accuracy of X-ray fluorescence and acid-digestion methods highly dependent on the equipment used and the experience of the operator. Dissolution can also be reported in terms of a measured alteration layer thickness or in terms of a calculated equivalent thickness. The term equivalent thickness refers to the glass thickness that must be leached in order to reach the observed concentration of an element in solution, usually expressed as 'boron equivalent thickness'121. While it is possible to report dissolution rates for all detectable elements within a glass, many of these elements participate in secondary phase formation and the dissolution rate must be represented using an element that is not present in the initial leaching solution (unless isotopic tagging is used) and not retained in the alteration layer. For borosilicate glasses, boron is the most commonly used tracer, with sodium, lithium or molybdenum (when present) also used ${ }^{122}$. These elements are highly soluble and poorly retained in secondary amorphous or crystalline alteration phases. Silicon can be used in dilute systems that remain undersaturated (e.g., for the SPFT method); however, it is not used in non-dilute conditions due to its role in the rate drop/residual rate regime. Where groundwater is used as the solution, the elements present in the solution must be considered, with tracer elements rarely found in natural minerals used (e.g., B, Mo).

\section{Measuring surface roughness}

As an alternative to monitoring aqueous species in solution, it is possible to quantify the rate of dissolution by measuring the reduction in mass or volume. Mass loss can be measured simply by drying and accurately weighing a sample before or after dissolution but, where very small changes in sample mass are 
expected, these changes may be too small to detect on a standard balance.

Following its successful use on a range of minerals to monitor crystal growth and dissolution, VSI has been applied to track dissolution under the dilute conditions of the SPFT, SCRA and MCFT tests where alteration layer formation is not expected $^{58,123,124}$. The difference in height between a covered reference and exposed reaction surface is detected through the phase difference between light hitting the sample compared to a reference with resolution down to $\sim 100 \mathrm{~nm}^{125}$. The height difference is proportional to the amount of glass dissolved. Icenhower and Steefel ${ }^{124}$ concluded that release rates calculated by measuring both solution chemistry and VSI were identical within experimental uncertainty. Small differences in dissolution rates attributed to the presence of a thin reaction layer leading to underestimation of surface retreat measured by VSI. VSI measurements can determine if the surface is dissolving uniformly or focused around surface features. It can also highlight if the glass is non-homogeneous in composition and if some areas are retreating faster than others. One limitation in achieving quantitative results is the need for a 'fresh', un-corroded surface from which to reference any surface retreat. This can be achieved by partial immersion or the use of a masking agent applied to part of the polished glass sample to prevent it coming into contact with the solution ${ }^{124}$.

\section{Specific surface area}

Since the dissolution rate is often normalised to the reactive surface area of the glass, accurate measurement of this property is essential in the determination of reaction kinetics. However, the determination of the precise reactive surface area for irregular crushed glass particles has been the subject of much debate $^{37}$. Brunauer-Emmett-Teller (BET)-specific surface area, measured by gas $\left(\mathrm{N}_{2}\right.$ or $\mathrm{Kr}$ ) molecule physisorption provides an accurate, to the atomic scale, quantification of the surface area taking into account nanoscale surface features. However, the role of these nanoscale features in the interfacial reactivity and the timescale of their evolution during surface layer formation processes is not well constrained. Moreover, BET tends to overestimate the reactive surface area, taking into account features that either do not partake in the dissolution reaction (e.g., cracks in the surface) or those which do (e.g., adhered fine particles not removed by washing), which results in lower than expected dissolution rates ${ }^{27,126}$.

The PCT method estimates the surface area from a geometric perspective, where the surface area of the particles is calculated by considering them as perfect spheres with a mean diameter of the upper and lower particle sizes and using the glass density. However, this tends to underestimate the particle surface area due to exclusion of small-scale surface features and adhered fine particles. It is generally accepted that using the geometric surface area for powdered samples yields dissolution rates that are comparable to those for monolith samples, and is considered a better estimate of the reactive surface area $37,61,110,126$. Given the discrepancies that arise between BET measurement and geometric estimation of surface area, the method of surface area determination must be taken into consideration when comparing results from different studies $^{37}$.

The SA/V ratio of a given glass powder particle can change significantly in dissolution methods that apply the use of high temperature (e.g., $\left.\geq 90^{\circ} \mathrm{C}\right)$ and/or extreme $\mathrm{pH}(<\mathrm{pH} 5$ and $>\mathrm{pH}$ 10 ), especially those run over long time frames (e.g., week or months rather than days). Under these conditions, the SA/V may constantly evolve, therefore the aqueous chemical measurements may not be appropriately normalised to the appropriate surface area, resulting in an underestimation of the dissolution rate. As described above, it is possible to recalculate the surface area throughout the dissolution experiment duration using the 'shrinking core' model, whereby a new surface area is calculated after each data point after a measured mass of glass material has been dissolved in solution 57,72 , however, this is not always practicable.

The preparation of glass coupons or monoliths, for example in the VHT, MCC-1 and EPA 1315 methods, is time consuming. It is, however, easier to measure the surface area of a geometric shape like a square or rectangular coupon as BET is less reliable on low surface areas. The geometric method is, however, only as reliable as the quality of the sample polishing with enhanced dissolution possible along scratches (see section 'Glass surface finish'). Although the coupon size or shape is not critical, it has become standard practice to use rectangular prisms of typical dimensions $10 \mathrm{~mm}$ by $10 \mathrm{~mm}$ by $\sim 5 \mathrm{~mm}$ to give a reactive surface area of around $400 \mathrm{~mm}^{2}$ (see ref. ${ }^{80}$ ).

\section{Glass surface finish}

Monolithic glass samples are typically cut with a rotating diamond blade but, prior to use in dissolution testing and depending on the test method applied, their surface finish may vary. They can either be left 'rough cut', ground, or polished, on one or more sides. A final polish usually ranges between 1 and $6 \mu \mathrm{m}$, achieved using diamond paste whereas a ground surface is finished at between 600 and 1200 grit. In a study of surface finishes, comparing 'as cut' samples with those polished with varying grades of silicon carbide paper, diamond paste, flame-polishing and thermal rupture methods, the greatest differences in dissolution rate were observed in the initial 7 days at $100^{\circ} \mathrm{C}$ using the Soxhlet method $^{127}$. As expected, faster dissolution rates were observed for unpolished specimens, presumably due to higher initial surface area, but the difference in dissolution rates reduced with longer exposure to the leaching solution, until the dissolution rates were identical for both cut and polished specimens after only 28 days. Flame polished and thermally ruptured specimens had fewer surface defects compared with the other methods of surface preparation (as determined by scanning electron microscopy and 3D surface scanning), and gave rise to lower dissolution rates over longer time periods, however, these methods are not used in routine dissolution testing, nor in any of the methods reviewed in the present work. Changing the surface polish influenced the dissolution rate in a similar manner, with smoother surfaces (i.e., higher grade of polish) giving lower glass dissolution rates, albeit in water vapour rather than liquid water ${ }^{128}$. It was hypothesised that the smooth finish limited the ability of water vapour to absorb to the glass surface and begin the dissolution reaction. The surface finish will likely be most important in dilute early-stage dissolution tests ${ }^{129}$, as surface area changes caused by gel layer formation and secondary-phase precipitation will outweigh those caused by microdefects on the glass surface ${ }^{27,126,130}$.

\section{Powdered glass washing}

In test methods that use powdered glass, the surface finish cannot be controlled, and the particle size distribution controls the amount of reactive surface. Sieves are used to isolate the particle size which is commonly between 74 and $149 \mu$ m (mesh size -100 to +200 ), with a washing step to remove any fines adhered to the powdered glass particles. As noted previously, these fine particles have a significant effect on surface area and the initial dissolution rate, particularly at low temperatures, since they are rapidly dissolved. Experiments performed at $22^{\circ} \mathrm{C}$ showed that the elemental release of $\mathrm{B}, \mathrm{Na}$ and $\mathrm{Si}$ from powdered glass material that was not washed, was twice that of material without fines ${ }^{99}$. It is the authors' experience that the washing protocols outlined in the PCT standard ASTM C1285 method (washing samples three times in water flowed by twice in an ultrasonic bath, then three times in ethanol) do not adequately remove fine particles, 
C.L. Thorpe et al.

Table 5. A summary of buffers and other chemical systems used to control the $\mathrm{pH}$ in glass dissolution tests.

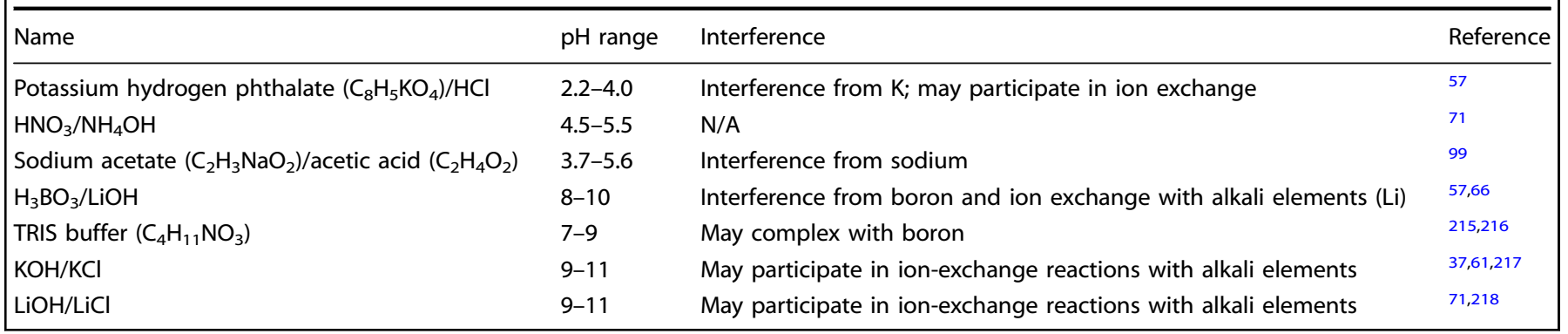

therefore repeated washing and ultra-sonication in isopropanol, until no more fines are observable on the surface, has been adopted in some laboratories (e.g., at the University of Sheffield as described in Mann et al. ${ }^{116}$.

\section{pH buffers}

The release of alkali elements into solution during aqueous glass dissolution results in a $\mathrm{pH}$ increase through the following reaction:

$\equiv \mathrm{Si}-\mathrm{O}-\mathrm{Na}+\mathrm{H}_{2} \mathrm{O} \rightarrow \mathrm{Si}-\mathrm{OH}+\mathrm{Na}^{+}+\mathrm{OH}^{-}$

In cases where a fixed $\mathrm{pH}$ is desirable in a test (e.g., SPFT, EPA 1313 and EPA 1315), a chemical buffer solution is used or the $\mathrm{pH}$ is constantly adjusted with acid or base. Different buffers are used to achieve the required $\mathrm{pH}$ in certain ranges of $\mathrm{pH}$ value, as summarised in Table 5. Ideally, the selected buffer should not interfere with the glass dissolution mechanism. Higher $\mathrm{pH}$ ranges (pH 9-12) can be attained using alkali chloride salts or alkali hydroxides e.g., $\mathrm{KCl} / \mathrm{LiCl}$ and $\mathrm{KOH} / \mathrm{LiOH}$ (not technically chemical buffers but chemicals that hold the system $\mathrm{pH}$ steady as the reaction progresses). The use of $\mathrm{NaCl} / \mathrm{NaOH}$ is avoided due to the high concentration of sodium in nuclear waste glass, while $\mathrm{Li}$ is also present in some nuclear waste glass compositions, e.g., UK MW2 $5^{72}$. Alkali buffers can participate in ion-exchange reactions with alkali elements $(\mathrm{Na}, \mathrm{K}$ and $\mathrm{Li})$ in the glass; studies have shown that $\mathrm{K}^{+}$ enhances the dissolution rate to a greater extent than $\mathrm{Li}^{+62,131}$. Tris (hydroxymethyl)aminomethane (TRIS) buffer is alkali-free and is generally agreed not to contribute to ion-exchange reactions with the glass, but it does possess the potential to complex boron released from the glass during dissolution ${ }^{132}$. Despite their clear advantage as buffers for use with glass, i.e., $\mathrm{NH}_{4}^{+}$should not participate in glass dissolution reactions, ammonia-based salts have not been widely applied. Acetic acid has been recommended to buffer solution $\mathrm{pH}$ instead of hydrochloric acid for the investigation of bioglass dissolution due to the role that chlorine plays in secondary mineral formation ${ }^{132}$.

\section{Vessel material}

The vessel materials specified in each standard test method are, on the whole, selected because they do not release elements into solution that will interfere with those released from the glass during the dissolution reaction. Thus, while some early tests did use glass vessels, it is commonplace to use stainless steel or heat resistant plastics, such as PTFE and HDPE. Stainless steel vessels can release iron and chromium but at quantities below the detection limit for short-term tests (weeks-months), provided the metal is not visibly corroded. Stainless steel is also routinely used for the PCT-A and VHT method.

Since vessel corrosion could cause interference with the dissolution reaction in longer-term dissolution experiments, PTFE (Teflon ${ }^{\circ}$ ) or PFA vessels are generally preferred. It is worth noting, however, that plastics are more susceptible to evaporative loss of solution (especially at temperatures of $>40{ }^{\circ} \mathrm{C}$ ) and that they allow slow ingress of $\mathrm{CO}_{2}{ }^{133}$ presenting challenges in experiments where an inert or $\mathrm{CO}_{2}$-free atmosphere must be maintained. In ASTM standard methods (e.g., the PCT-B and MCC-1 methods) a cleaning procedure is recommended for new Teflon vessels to ensure that they are free of fluoride ions that can affect the solution $\mathrm{pH}$ through formation of HF. In this procedure, the vessels are heated for at least 7 days being $90 \%$ full of $\mathrm{NaOH}$ and, after rinsing steps, for a further $>16 \mathrm{~h}$ in DI water (ASTM, C1285) ${ }^{78}$. Teflon vessels are suitable for use in radiation fields of up to $1 \times$ $10^{5} \mathrm{rad}$ (alpha/beta) but beyond this material breakdown can occur leading to further release of $\mathrm{F}^{-}$ions ${ }^{78}$. In all experiments discussed, blanks are used to ensure that any leaching of elements from the experimental set-up can be accounted for.

\section{Multiphase glass materials}

Despite careful design, higher activity waste glasses are not always homogenous. For example, certain glass compositions and preparation conditions can result in the phenomenon of immiscibility, giving rise to 'glass-in-glass' phase separation, or the formation of crystalline inclusions, such as nepheline $\left(\mathrm{NaAlSiO}_{4}\right)$, which can form during canister cooling ${ }^{134,135}$. Lower-activity wastes, especially those synthesised by incontainer techniques, are often multiphase glass ceramics ${ }^{9,136}$. The presence of multiple phases can result in the preferential attack of the immiscible phase with lower chemical durability. Analysis of post-dissolution samples (e.g., by SEM) provides evidence for localised accelerated dissolution, indicative of preferential attack ${ }^{71,137,138}$, although localised features can also result from dehydration cracking of alteration layers when subjected to the SEM vacuum ${ }^{139}$. In amorphous and crystalline phase-separated glasses, there is often a dominant or host phase and a minor or inclusion phase, with one fraction dissolving at a different rate when compared to the other ${ }^{77,140}$. Using the standard test protocols, which are applied to the bulk material, the different rates of dissolution cannot be distinguished. Crystalline phases can have small effects (e.g., the formation of some spinel phases), or significant negative effects (e.g., the precipitation of nepheline $\left.\left(\mathrm{NaAlSiO}_{4}\right)\right)$, on the durability of nuclear waste glasses ${ }^{134,141}$. Wastes containing high $\mathrm{Al}_{2} \mathrm{O}_{3}$ and high $\mathrm{Na}_{2} \mathrm{O}$ coupled with lower $\mathrm{SiO}_{2}$ are particularly prone to nepheline crystallisation and therefore melt chemistry is carefully controlled to reduce susceptibility.

Whilst some standard methods specify that they are intended for use on ceramic and glass-ceramic material (e.g., PCT, ANS 16.1, and $M(C-1)$, others are not. Tests designed to measure the forward rate will be complicated by differing dissolution rates between phases and will not be able to calculate the dissolution rate of a single phase by aqueous chemistry measurements alone. Here, techniques like VSI could be employed to measure the loss of material from the various phases (see section 'Measuring surface roughness'). 


\section{Timescale}

Most of the standard test methods described in this review stipulate a duration of approximately one month or less. While this may be entirely appropriate, depending on the SA/V ratio, temperature and $\mathrm{pH}$ conditions imposed, such timescales are not always adequate to fully capture the glass dissolution kinetics and mechanisms necessary for input to the post-closure safety assessment of radioactive waste disposal facilities. With the notable exceptions of tests aiming to measure the forward or initial rate, the longer a glass experiment can run the better, to ensure that the evolution of the alteration layer and possible rate resumption are captured. However, this is not always practicable; the short time scales of scientific employee contracts, student training (3-5 years) and even the lifetime of various equipment, reduces the continuity required for long-term ( $>10$ years) accelerated dissolution investigation. One study reported that the onset of the residual rate of SON68 (in UHQ at $90^{\circ} \mathrm{C}$ ) was observed after 365,100 and 10 days for SA/V ratios of 12,80 and $2000 \mathrm{~m}^{-1}$, respectively ${ }^{31}$. The standardisation of test methods over such durations presents a challenge in itself; for example, one only has to refer to Table 3 to understand that numerous standard methods have been consistently, and relatively frequently (at least on the timescales of glass dissolution) updated, tweaked and altered in the 40 years since they were first used.

\section{Test atmosphere}

All the tests described above are conducted under oxic conditions. In contrast, many disposal sites, especially those located at greater depths, are expected to be anoxic due to the consumption of available oxygen by microbial processes, the corrosion of metallic containers and the generation of $\mathrm{H}_{2}(\mathrm{~g})$. The prevailing oxygen partial pressure of the environment can have a profound effect on the release of redox-active species such as iron and uranium ${ }^{142}$ as they form different species upon release from the glass network. It is possible to adapt many of the tests above to oxygen or $\mathrm{CO}_{2}$ free atmosphere by either setting them up within a glove box or anaerobic chamber or using a sealed bespoke reactor if heating within an oven is required. Figure $5 \mathrm{c}$ shows the set-up of PCT tests within a controlled atmosphere at $90^{\circ} \mathrm{C}$ as conducted at the University of Sheffield. The bespoke reactor is a large metal container or 'bean tin' that is sealed and placed within an oven, designed and developed by Boast ${ }^{143}$. Gas is continuously circulated through the reactor via inlet and outlet pipes, through the top of the tin and oven, to maintain the desired atmosphere for the duration of the experiment ${ }^{116,143}$.

\section{APPLICATION OF STANDARD METHODS TO A STANDARD ALKALI-BOROSILICATE GLASS}

In this section, we review the available published data collected from the standard test methods described above on a standard glass material with the intention of demonstrating the range of information that can be acquired and how these data compare between tests.

A reference glass is a generic glass formula that is designed to be used for interlaboratory comparisons. A complex reference glass, the Environmental Assessment Glass (EA Glass) was developed in the 1980s. It had a known chemical and redox composition and was intended to be used as a benchmark HLW glass: other waste glasses could be reported as more or less durable than the EA glass (Table 1$)^{144}$. More recently, the ISG was developed from the French SON68 nuclear waste simulant glass, which itself is a non-radioactive surrogate for R7T7, the French high-level nuclear waste composition. The 6-component alkali-borosilicate ISG reference was intended to improve the comparability of results from international interlaboratory investigations to understand the mechanisms controlling glass dissolution ${ }^{145,146}$.

The ISG has a density of $2.50 \times 10^{-3} \mathrm{~kg} \mathrm{~cm}^{-3}$ and a target composition of $\mathrm{SiO}_{2}$ (60.10 mol\%), $\mathrm{Na}_{2} \mathrm{O}$ (12.65 mol\%), $\mathrm{B}_{2} \mathrm{O}_{3}$ (15.97 mol\%), $\mathrm{Al}_{2} \mathrm{O}_{3}$ (3.84 mol\%), $\mathrm{CaO}$ (5.73 mol\%) and $\mathrm{ZrO}_{2}$ $(1.72 \mathrm{~mol} \%)^{145,147}$.

Since its advocation in Gin et al. ${ }^{145}$, there have been over 30 studies using ISG to explore aspects of glass dissolution behaviour including, but not limited to, the effect of individual elements ${ }^{148-152}$, the influence of specific disposal environments ${ }^{71,116}$ and the effects of glass surface properties. Several studies have investigated the dissolution of the ISG in solutions other than ultra-pure water, for example, Elia et al. ${ }^{117}$ and Mann et al. ${ }^{116}$ performed dissolution tests in $\mathrm{KOH}$ and young cement water to assess the effect of cement leachate on ISG dissolution. The solution choice has a significant effect on the test output data and therefore only studies using ultra-pure water are presented here for comparison.

\section{Determination of International Simple Glass forward dissolution rate}

The application of the SPFT standard method (see section 'Glass durability under dilute conditions') to determine the forward rate of ISG dissolution was performed by Neeway et al. ${ }^{59}$ and Backhouse et al. ${ }^{71}$. The two studies used an almost identical experimental set-up with the ISG crushed to the same size fraction and sourced from the same company (MoSci Corporation, Rolla, MO, USA). The surface area in both studies was estimated using the geometric formula ${ }^{57}$ (see the section 'Specific surface area'), the SPFT apparatus was comparable, both using a similar $\mathrm{q} / \mathrm{S}$ and using syringe pumps to maintain a target flow rate of $40 \mathrm{~mL} / \mathrm{d}$ and $10-80 \mathrm{~mL} / \mathrm{d}$ for Neeway and Backhouse respectively. Backhouse et al. used TRIS buffer ( $\mathrm{pH} \mathrm{7,} 9$ and 11), a LiCl/LiOH buffer ( $\mathrm{pH} 12)$ and an $\mathrm{HNO}_{3} / \mathrm{NH}_{3} \mathrm{OH}$ buffer (pH 4.5 and 5.5) whilst Neeway et al. used TRIS buffer (pH 9 and 10) and $\mathrm{LiCl} / \mathrm{LiOH}$ (pH 11 and 12) (see the section ' $\mathrm{pH}$ buffers'). Backhouse et al. investigated ISG dissolution at temperatures of 40,50 and $70^{\circ} \mathrm{C}$, whilst Neeway et al. covered a larger temperature range of $22,40,70$ and $90^{\circ} \mathrm{C}$. Backhouse et al. performed linear multivariate regression (LMR) on their experimental data to determine model parameters $\log ^{10} \mathrm{k}_{0}, \eta$ and $E_{a}$ (see the section 'Glass durability under dilute conditions'). Neeway et al. compared both LMR and nonlinear multivariate regression using the GCMT software package ${ }^{153}$ finding that the two methods resulted in similar mean values within one standard deviation. The dissolution rate results of both studies are presented in Fig. 7 and activation energies are presented in Table 6 for alkaline conditions only.

These data can be compared to an ISG study by Inagaki et al. ${ }^{61}$ who used the MCFT method (see section 'Glass durability under

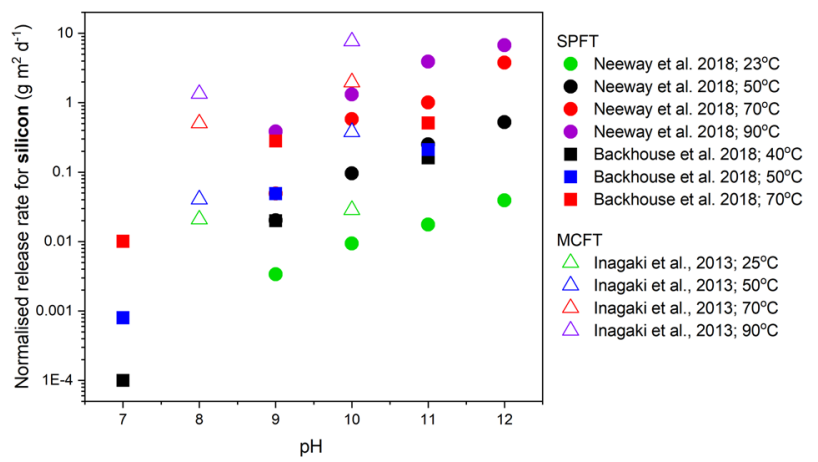

Fig. 7 Comparison of forward dissolution rate data for ISG. Comparison of the normalised forward dissolution rates of silicon obtained from three studies of the ISG in the alkaline $\mathrm{pH}$ range, using the SPFT and MCFT test methods. 
Table 6. Activation energies reported for the ISG under alkaline conditions.

\begin{tabular}{lll}
\hline $\begin{array}{l}\text { Activation energy under alkaline } \\
\text { conditions }\end{array}$ & Method & Reference \\
\hline $77 \mathrm{~kJ} / \mathrm{mol}$ & MCFT & 61 \\
$71.5 \mathrm{~kJ} / \mathrm{mol}$ & SPFT & 61 \\
$80 \pm 4 \mathrm{~kJ} / \mathrm{mol}$ & SPFT + LMR & 59 \\
$81 \pm 4 \mathrm{~kJ} / \mathrm{mol}$ & SPFT + GCMT & 59 \\
$* 77.4 \pm 4.7 \mathrm{~kJ} / \mathrm{mol}(\mathrm{Si}) * 79.5 \pm 3.5 \mathrm{~kJ} / \mathrm{mol}(\mathrm{B})$ & SPFT + LMR & 71 \\
\hline
\end{tabular}

"Kinetic parameters reported separately for $\mathrm{Si}$ and $\mathrm{B}$ datasets. All other papers report the activation energy for the ISG as a whole.

dilute conditions'). Despite both methods using flow-through conditions and claiming a dilute solution, they yield slightly (within the same order of magnitude) different dissolution rates for the forward rate and kinetic parameters (Fig. 7 and Table 6). The forward dissolution rate of Si was consistently lower, by a factor of between 2 and 7 (within an order of magnitude) when measured by SPFT compared to MCFT. The main difference between the two methods is in the more accurate estimation of surface area that is possible when using a monolith with a channel engraved into it (MCFT) rather than a crushed and sieved powder (SPFT). To avoid the issue of fines, SPFT experiments are performed over a long time period and data taken from near to the end when the rate is at steady state and the fines are assumed to have dissolved. Backhouse et al. ${ }^{71}$ suggested that, although in agreement with Neeway et al. $^{59}$, data from their higher temperature range $\left(70^{\circ} \mathrm{C}\right)$ might not represent forward rate conditions. They observed features resembling dehydration cracking on high-temperature samples, indicating the presence of a gel layer and noted a continued reduction in dissolution rate with time over 120 days suggesting a steady state was not being maintained. It was also suggested that the higher flow rates used by Inagaki et al., ${ }^{61}$ in the MCFT method may have contributed to higher dissolution rates through physical erosion of the sample surface. The only other major difference between the two set-ups was the use of different solutions to control the $\mathrm{pH}$ with Inagaki et al. opting for a $\mathrm{KCl} / \mathrm{KOH}$ solution at alkaline $\mathrm{pH}$ that may have contributed in ion-exchange reactions to a greater extent than $\mathrm{LiCl} / \mathrm{LiOH}$ solution used by Neeway et al. and Backhouse et al. Despite this, the activation energies obtained from the application of the MCFT and SPFT methodologies to the ISG in the alkaline pH range were generally in good agreement, as shown in Table 6. These values $\left(70-80 \mathrm{~kJ} \mathrm{~mol}^{-1}\right)$ indicate that the forward rate is controlled by surface reactions rather than diffusion-controlled processes $\left(30-50 \mathrm{~kJ} \mathrm{~mol}^{-1}\right)^{25,39,61}$.

\section{Determination of International Simple Glass initial and residual dissolution rates}

In order to determine the initial rate, data must be gathered over a short time period where the rate remains constant before the rate-drop regime. The initial rate has been found to be highly dependent on the test methodology and on the sample preparation techniques used as this is the stage most influenced by fine particles and surface finish. To demonstrate the importance of sample surface area estimation on calculated initial rates, Fournier et al. ${ }^{27}$ conducted a comparison study of initial rates determined by SPFT, MCFT, static powder tests (e.g., PCT) with surface area determined by the geometric method and BET method (see section 'Specific surface area'), and static monolith tests (e.g. MCC-1). All tests were conducted on the ISG at a temperature of $90^{\circ} \mathrm{C}$. In the study by Fournier et al. ${ }^{27}$, no distinction was made between the forward rate, as determined by steady release over a long time period (as in the SPFT method) and the initial rate estimated from the initial hours of a static experiment. The range of initial rates obtained by the different methods that nevertheless fell within the same order of magnitude with SPFT unsurprisingly giving the consistently highest results. Interestingly, in this study, rates estimated by MCFT were lower than SPFT, which is in contrast to a comparison of results obtained by Inagaki et al. ${ }^{61}$ and Neeway et al. ${ }^{59}$. Although it is encouraging that all initial rate calculations fall within the same order of magnitude for both powder and monolith samples, this study implies that monolith studies give the most consistent estimate of initial rate with static tests showing good agreement with flowing tests. Another investigation into the initial rate of dissolution performed on ISG glass compared initial rates measured in static PCT style tests with stirred and end-over-end tumbled tests (Fig. 8a and Table 7).

Figure 8a clearly shows the difference between an agitated (in this case stirred) PCT test compared to an unstirred test conducted under the same conditions. These tests were conducted using the same batch of glass, crushed, sieved and washed by the same researcher. A rate of $0.005 \pm 0.0002 \mathrm{~g} \mathrm{~m}^{-2} \mathrm{day}^{-1}$ was calculated for the unstirred PCT compared to a rate of $0.007 \pm 0.0002 \mathrm{~g} \mathrm{~m}^{-2}$ day $^{-1}$ for the stirred test (Table 7). Although particle collisions may contribute in a minor way to the increased release of elements from solution, the major differentiating factor is thought to be the avoidance of localised saturation and particle coalescence in PCT tests that are conducted under static conditions (see section 'Glass durability under static non-dilute conditions').

Residual rate data is available measured from PCT type static powder dissolution tests conducted in UHQ water at temperatures between 25 and $90^{\circ} \mathrm{C}$ for time periods ranging from 28 to $>454$ days $^{83}$. The higher the temperature, the faster the reaction progresses with one study reporting a rate 43 times lower than the forward rate after just 7 days of dissolution in a static test at $\mathrm{pH} 9$ and temperatures of $90^{\circ} \mathrm{C}^{154}$. In another study, data from static powder dissolution tests conducted at $50^{\circ} \mathrm{C}$ for up to 454 days is presented in Fig. $8 \mathrm{~b}$ demonstrating that the residual rate is not constant and shows a continual decrease over timescales of 454 days under the test conditions used ${ }^{83}$.

The ISG has been used recently to study the phenomenon of rate resumption using a technique of seeding zeolite species onto the glass surface, eliminating the time that it takes for these minerals to precipitate ${ }^{155}$. Resumption of the rate of dissolution was observed to be less pronounced with decreasing $\mathrm{pH}$ and temperature and was observed to be no longer detectable at around $\mathrm{pH}$ 9, the natural $\mathrm{pH}$ of ISG glass when dissolving in UHQ at $90^{\circ} \mathrm{C}$ and a SA/V of $\sim 2000 \mathrm{~m}^{-1}$. The study shows that even at high $\mathrm{pH}$ and high temperature the 'resumption rate' observed was lower than the 'initial rate' meaning that the forward rate is likely the fastest that ISG can dissolve.

The variations obtained in forward, initial, and residual rates, as measured by different tests, even when testing a simple glass-like ISG in DI water are significant. This example highlights the need to understand each test and its limitations before use.

\section{Determination of International Simple Glass elemental release as a function of $\mathrm{pH}$}

All of the data presented in section 'Determination of International Simple Glass Initial and Residual Dissolution Rates' were taken from experiments with a final $\mathrm{pH}$ of 9-9.5, the natural $\mathrm{pH}$ of the glass when exposed to UHQ water at high SA/V ratios $\left(\sim 2000 \mathrm{~m}^{-1}\right)$. Tests such as the EPA 1313 fix the $\mathrm{pH}$ using additions of nitric acid or alkali hydroxide to explore glass dissolution as a function of hydrogen ion concentration (see section 'Glass durability under agitated non-dilute conditions'). The elemental release rate of ISG subjected to this test follows a 
a

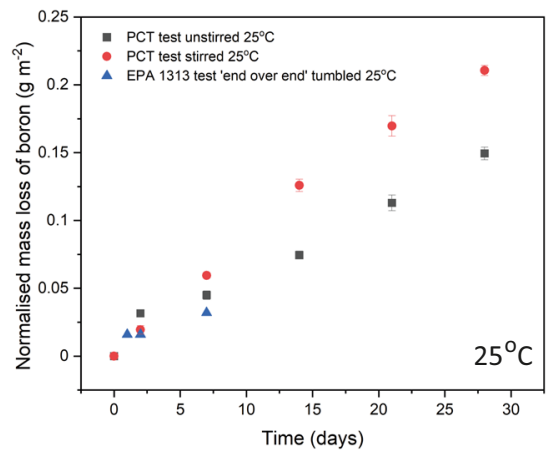

b

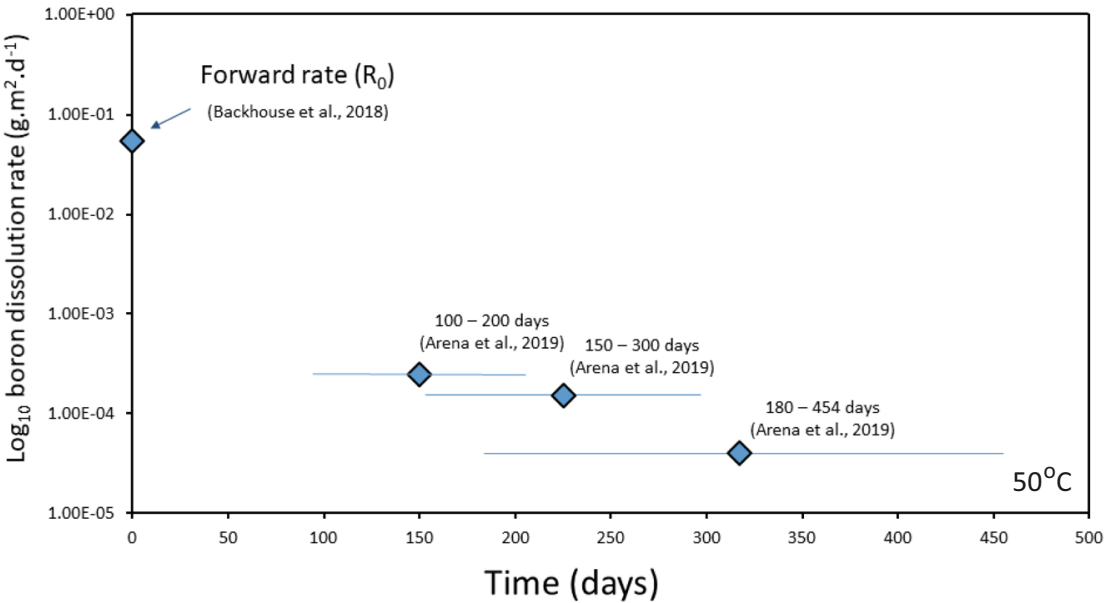

Fig. 8 ISG dissolution under the initial and residual regime. a Normalised mass loss of boron for test conducted on ISG in ultra-pure water at $25^{\circ} \mathrm{C}$. Black squares $=P C T$ test unstirred, SA $/ \mathrm{V}$ ratio $2000 \mathrm{~m}^{-1}$, red circles $=P C T$ stirred test SA $/ \mathrm{V}$ ratio $2000 \mathrm{~m}^{-1}$ and blue triangles $=E P A$ 1313 test, end over end tumbled, SA/V ratio $2000 \mathrm{~m}^{-1}$. Errors bars are the standard deviation of duplicate analysis. b Normalised release rate of boron $\left(\mathrm{g} \mathrm{m}^{-2} \mathrm{~d}^{-1}\right)$ from ISG measured by static PCT-B type test at $50^{\circ} \mathrm{C}$ at the natural system pH of $\sim 9.3$ over timescales of $90-454$ days ${ }^{83}$ and the forward rate at $\mathrm{pH} 9.0$ measured at $50{ }^{\circ} \mathrm{C}^{71}$. Release rates are plotted at the midpoint of the timeframe indicated by the corresponding horizontal line.

Table 7. variability in initial rate calculation from short-term tests measured in UHQ.

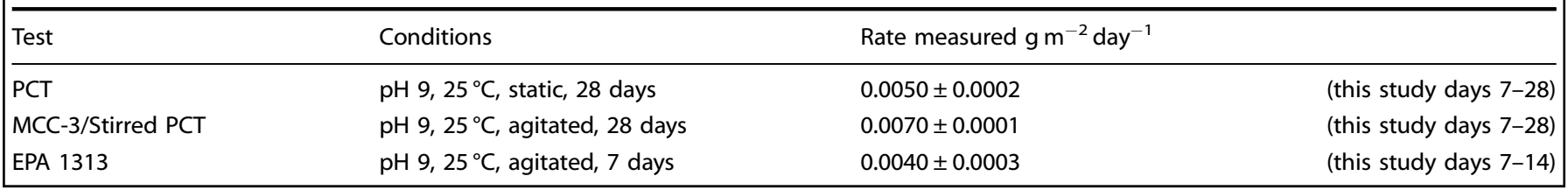

typical U-shaped dependency (Fig. 9) with the minimum in release observed at $\mathrm{pH}$ of $\sim 9$ and increasing release towards the extremes of both acidic and alkaline conditions.

Release of elements from ISG, as for other glasses, was fastest in the first $24 \mathrm{~h}$ with release rates increasing only moderately when the test was performed for longer time periods. Measurements of silica in solution (data unpublished) indicate that silica saturation was reached at $\mathrm{pH}<4$ over a 7-day time period meaning that at extremes of $\mathrm{pH}$ reaction progress had proceeded beyond the initial rate regime. This is a consideration when comparing across the $\mathrm{pH}$ range, especially over longer timescales and higher temperatures, where some $\mathrm{pH}$ points will enter the rate-drop regime ahead of others.

The EPA 1313 data for $\mathrm{pH} 9.5$ showed good agreement when plotted against stirred and unstirred PCT data (Fig. 8b). As EPA 1313 is an end-over-end tumbled test, release rates might have been expected to be higher however these experiments were conducted on the bench where temperature control was not absolute and using glass that was crushed, sieved and washed by a different researcher. These differences alone are enough to create differences in short-term test results. Another key difference between the two test methods is that the EPA 1313 sets the $\mathrm{pH}$ via acid/alkali addition at the experiment start point such that the final $\mathrm{pH}$ will be a specific value (in this case 9.5). In the PCT tests, $\mathrm{pH}$ is left to stabilise (usually within $24 \mathrm{~h}$ ) to a pH determined by the glass. Although the end $\mathrm{pH}$ in each experiment was the same the initial $\mathrm{pH}$ may have differed.

Overall, compiling results from tests performed on ISG highlights the variability in test response even when performed on a simple homogeneous glass in DI water. Methods designed to measure either the forward rate (SPFT and MCFT) or initial rate (static monolith and static powder) produced results within the same order of magnitude but with some variability between methods attributed largely to differences in surface area estimation (Figs. 7 and 8a). Measurements of the residual rate were shown to be highly dependent on the timeframe of the 


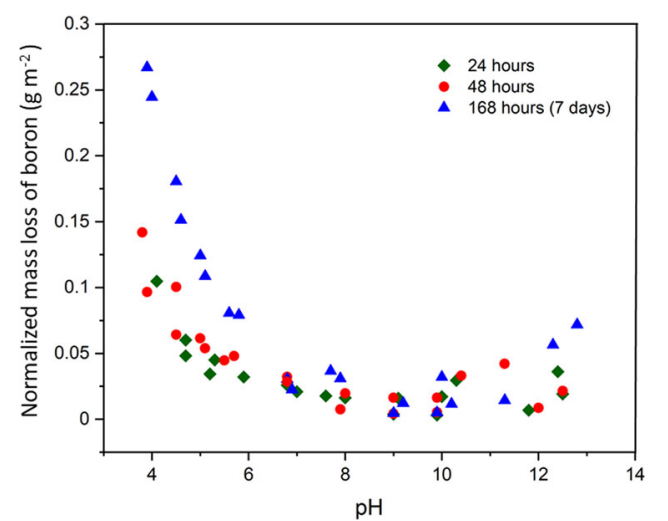

Fig. 9 EPA 1313 performed on ISG. EPA 1313 performed at $25^{\circ} \mathrm{C}$ for 24,48 and $168 \mathrm{~h}$. Each data point represents an individual sample vessel and the $\mathrm{pH}$ of the solution in each sample vessel at the experiment endpoint is plotted against the normalised mass loss of boron.

experiment even when conducted at the same temperature posing the question of whether the residual rate requires further definition (Fig. 8c). Tests designed to show leaching response as a function of $\mathrm{pH}$ (in this case, EPA 1313) demonstrate the U-shaped $\mathrm{pH}$ profile for the ISG but may be measuring a different stage of glass dissolution at the extremes of $\mathrm{pH}$ than in the middle of the range due to differences in $\mathrm{Si}$ saturation.

\section{THE FUTURE OF ACCELERATED GLASS DISSOLUTION METHODS: A PERSPECTIVE}

\section{Glass testing: $\mathbf{4 0}$ years and beyond}

During the last 40 years, an international effort has designed, adapted, and tested methods to measure elemental release from and derive dissolution rates for vitrified waste forms. Tests have continued to evolve with our understanding of glass dissolution mechanisms, and the need to assess the long-term performance of glasses, in addition to their consistency on the production line.

Since the 1980's considerable scientific advances have been made, particularly in the field of solid-state characterisation. It is now possible to use techniques such as atom probe tomography (APT), transmission electron microscopy (TEM), Tof-SIMS and Synchrotron-based Microfocus X-ray Techniques (microfocus $X$-ray diffraction ( $\mu \mathrm{XRD)}, \mathrm{X}$-ray fluorescence $(\mu \mathrm{XRF})$ and X-ray absorption near-edge spectroscopy ( $\mu$ XANES)) and Scanning Transmission Electron Microscopy (STEM) to probe the composition and mineralogy of glass-alteration layers. Elemental and isotopic profiling techniques, like Tof-SIMS, have allowed the use of isotopes (e.g., ${ }^{30} \mathrm{Si} /{ }^{29} \mathrm{Si} /{ }^{28} \mathrm{Si},{ }^{18} \mathrm{O} /{ }^{16} \mathrm{O}$ and ${ }^{2} \mathrm{H} /{ }^{1} \mathrm{H}$ ) to differentiate between elements derived from the glass and those from solution giving new insight into the formation of the alteration layers $40,90,156$. Advances in imaging, elemental mapping and $X$-ray diffraction techniques have allowed the characterisation of amorphous and crystalline alteration products with the aim of establishing a link between alteration layer composition, the alteration environment and the glass dissolution rate ${ }^{116,120}$. Although scientific advances have improved our understanding of glass corrosion processes, elemental release data provided by standard glass dissolution tests are still required. From the point of view of a regulator assessing the safety case for vitrified radioactive waste disposal in a subsurface or near-surface repository, it is the release of elements of concern into a solution that are of interest.

Another major change since the first dissolution tests for glass 40 years ago is their application to new heterogeneous waste forms such as highly durable ceramics and glass ceramics. Tests including the SPFT, MCC-1 and PCT, have been applied to ceramic waste forms to estimate their dissolution rate and release of elements such as plutonium ${ }^{157-159}$. Due to the higher durability of many ceramic waste forms, testing timeframes may be longer than those used for glasses to achieve measurable elements in solution. In the UK, mixed intermediate-level wastes (ILW) are being considered for thermal treatments and often result in a heterogeneous product containing glass, crystalline and sometimes metallic slag like fractions $s^{11,142,160-162}$. These add challenges as different phases will have different dissolution rates and alteration behaviour, meaning the measured dissolution rate may not represent the corrosion of the waste form as a whole. In these cases, it is important to focus simple dissolution tests on the release of elements of most concern and to ascertain in what phase these elements are present.

\section{Validation of glass testing methodology and applicability to complex natural environments}

Simplified laboratory experiments, conducted under simplified sterile conditions, do not take account of all factors that may influence long-term glass corrosion. These factors will be complex and varied in disposal environments and include variable saturation, climate cycling, geochemical changes, and the direct or indirect effect of microbial metabolism. It is important to verify if laboratory alteration is representative of that observed under field conditions, especially as regards alteration layer chemistry/ mineralogy that control long-term release rates. Furthermore, as most studies are conducted on model glasses and inactive surrogates, the effects of radiation damage and gradual cooling are not accounted for. In order to validate laboratory-based approaches, comparison with corrosion observed on natural and archaeological analogue glasses can be useful. Such analogues require glassy materials to have been exposed to water or water vapour for a known time, under known geochemical conditions. Due to uncertainties, that increase with the age of the sample, and the chemical dissimilarities between nuclear waste glasses and most analogues, no single analogue can be used to verify glass corrosion mechanisms for all compositions and in all disposal environments, but rather the collective results of many studies may be considered.

The degradation of natural and archaeological analogue glasses has been extensively reviewed ${ }^{163-167}$. Among the most useful, are comparisons studies using basaltic glasses ${ }^{168,169}$, archaeological glasses from aqueous environments ${ }^{170}$ and vitrification found at a 3000 year of hillfort ${ }^{171-173}$. In addition, a number of long-term in situ glass corrosion experiments have been established with nuclear waste simulant glasses, including borosilicate glass in Boom clay ${ }^{119}$, in salt ${ }^{174}$, granite ${ }^{175,176}$, sediments ${ }^{177,178}$ and limestone lithologies ${ }^{179-181}$. Long-term studies on both simulant, and radioactive, nuclear waste compositions in representative environments exist at nuclear sites. Examples include radioactive HLW emplaced in a lysimeter at the Savannah River Site ${ }^{177}$ and Hanford Site ${ }^{182}$, in situ testing of borosilicate glasses emplaced in boom clay at the HADES facility, Belgium ${ }^{183}$ and field corrosion tests at the Russian LILW disposal site, Radon ${ }^{77}$. Experiments on the timescale of several years/decades are highly desirable to further define the residual rate of a reaction under conditions close to repository conditions.

Where higher-level wastes are concerned, radiation and radiation damage may influence glass durability and therefore studies on active glasses are extremely valuable. Such studies are few with some studies indicating greatly increased degradation in active glasses $^{184-188}$ whist others imply little or no change ${ }^{189,190}$.

Work on glass corrosion in complex environments and the study of natural analogue glasses is an international endeavour. These studies, and their comparison to accelerated glass dissolution performed using standardised methods, will become 


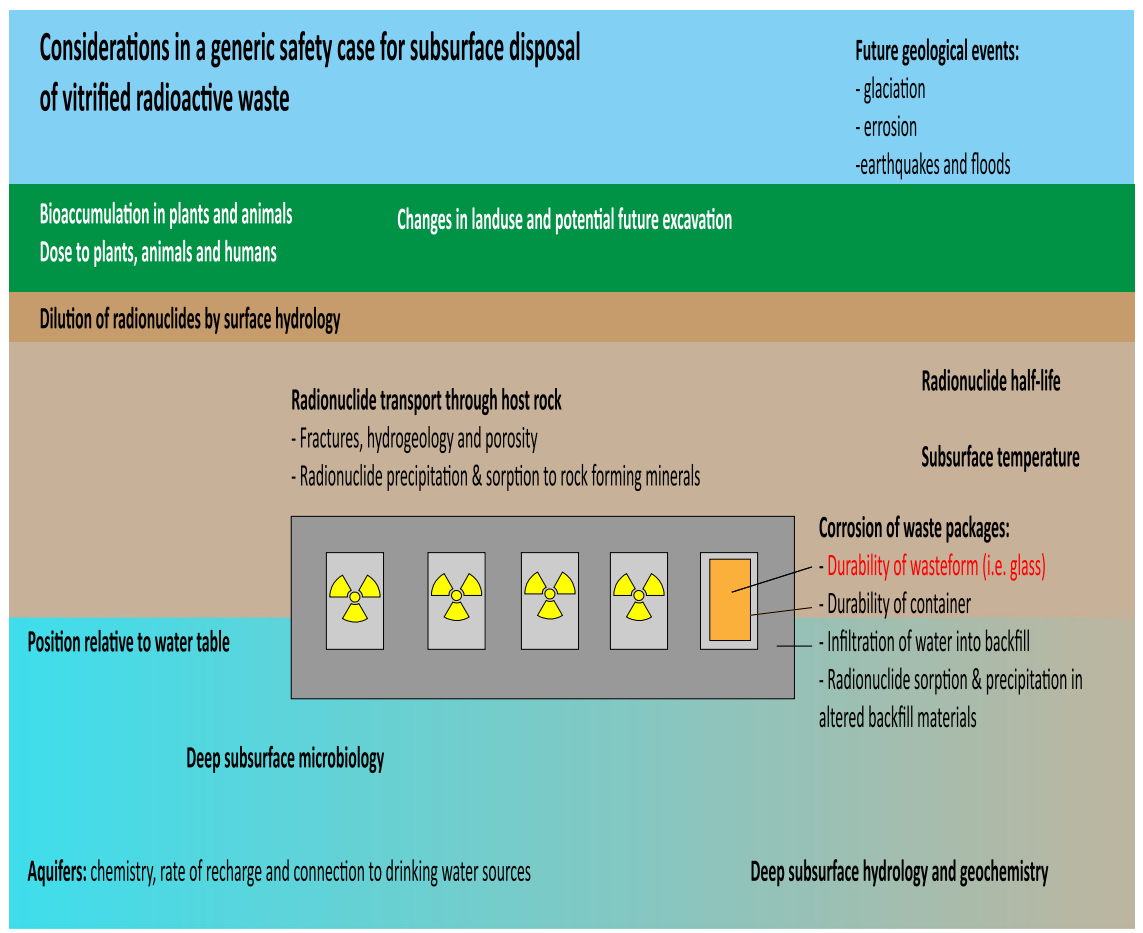

Fig. 10 Considerations in subsurface disposal of radioactive waste. Schematic illustrating some key considerations in the safety case for subsurface disposal of radioactive waste.

increasingly relevant as countries move into site selection and environmental conditions can be better constrained.

\section{Glass durability testing in the context of safety case and performance assessment}

Although the long-term performance of different glass compositions will have been considered, as far as possible, at the time of manufacture, many glasses have been formulated with only a generic disposal concept available. As countries move from disposal concept design to disposal implementation, glass durability assessments can focus on more specific disposal conditions providing dissolution rate data to support the safety case for disposal and accompanying safety assessment/performance assessment for each disposal site ${ }^{191}$. The IAEA states that the safety case is a 'collection of scientific, technical, administrative and managerial arguments and evidence in support of the safety of a disposal facility' and within this, the performance/safety assessment 'involves quantification of radiation dose and radiation risks that may arise from the disposal facility' and 'provides an understanding of the behaviour of the disposal facility under normal conditions and disturbing events, considering the time frames over which the radioactive waste remains hazardous ${ }^{\prime 191}$.

There are two methods by which regulatory bodies can set disposal criteria. The regulator could specify a test, and test response, that must be met prior to waste acceptance for disposal, as is often the case in waste production (as in the US). Alternatively, no threshold test or response is set with waste acceptance instead dependent upon a required containment lifetime. At present, a no threshold test is set in most European countries with a 'no threshold' approach generally preferred. The European Horizon 2020 THERAMIN project supported by France, UK, Germany, Belgium, Finland, Slovakia and Lithuania concluding that: 'If criteria relating to the durability of a thermally treated (vitrified) waste form are deemed to be required for application in a particular context, then it is recommended that these should be linked to a required containment lifetime (as assumed in the relevant post-closure safety case), rather than to a threshold dissolution rate. ${ }^{\prime 192}$. After site selection, this approach will allow a range of tests to be performed under site relevant conditions.

The choice of test for a given purpose, and those that have evolved to be most widely used, is greatly influenced by ease and expense. This effect is compounded by a desire to compare results obtained from a new glass with those of other existing glasses and standards. A large body of comparative literature exists for tests that are relatively quick and simple to perform and that require inexpensive apparatus, for example, the PCT and MCC-1 standard methods, especially where the use of radioactive samples requires apparatus that can be used inside a glove box. In contrast, methods that require complicated apparatus and significant time to acquire results, for example, the MCFT and PUF, have been performed less often and in fewer locations leading to fewer datasets being available for comparison. In this way, choices made regarding future experiments are influenced by past studies even down to specific details such as particle/coupon size and liquid/ solid ratio. In many cases, it is easier, for regulatory purposes, to implement a test already approved for another site or material than to design and validate a new test that would require an extended period of testing and validation.

Initiatives also aim to develop models to produce input data for use in performance assessment with several glass dissolution models under development. In France, where the disposal concept is centred on one fixed glass composition (R7T7) in clay geology, the GRAAL modal (Glass Reactivity Accounting for Alteration Layer) uses kinetic parameters intrinsic to each glass composition to predict long-term performance of R7T7 under site relevant conditions. The GRAAL model is based on transition state theory with a passivating reactive interphase (PRI) that limits diffusion from the pristine glass and aims to estimate the long-

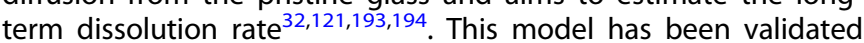
against archaeological samples but not yet successfully applied across a wider range of glass compositions ${ }^{32,193}$ and is being adapted for use on UK HLW ${ }^{195}$. The Hanford site ILAW performance assessment model is also based on transition state 
theory but uses a separate and constant ion-exchange rate (i.e. $\mathrm{H}^{+}$ from the solution that exchanges for $\mathrm{Na}^{+}$in the glass) to prevent the glass dissolution rate from going to zero ${ }^{196}$.

Building confidence in our understanding of glass dissolution and how fast radionuclides will be released is important and part of the wider safety assessment for any potential disposal site. Figure 10 illustrates some of the many considerations for the long-term disposal of radioactive waste, showing how the release of elements from glass, under site relevant conditions, is part of this bigger picture. An international effort is underway to use laboratory testing, validated by field experiments, to understand the behaviour of varied glass compositions in a wide range of environments considered for the disposal of vitrified radioactive wastes.

\section{DATA AVAILABILITY}

The datasets generated during and/or analysed during this study are available from the corresponding author on reasonable request.

Received: 4 May 2021; Accepted: 25 November 2021; Published online: 20 December 2021

\section{REFERENCES}

1. Jantzen, C. M. Historical development of glass and ceramic waste forms for high level radioactive wastes. In Handbook of Advanced Radioactive Waste Conditioning Technologies. (ed Ojovan, M. I.) Ch. 6, 159-172 (Woodhead, 2011).

2. Jantzen, C. M. Development of glass matrices for high level radioactive wastes. In Handbook of Advanced Radioactive Waste Conditioning Technologies (ed Ojovan, M. I.). Ch. 9, 230-292 (Woodhead, 2011).

3. Jantzen, C. M., Lee, W. E. \& Ojovan, M. I. Radioactive waste (RAW) conditioning, immobilisation, and encapsulation processes and technologies: overview and advances. In Radioactive Waste Management and Contaminated Site Clean-up: Processes, Technologies and International Experience (eds Lee, W. E., Ojovan, M. I. \& Jantzen, C. M.). Ch. 6, 171-272 (Woodhead, 2013).

4. Kim, C. W., Park, J. K. \& Hwang, T. W. Analysis of leaching behavior of simulated LILW glasses by using the MCC-1 test method. J. Nucl. Sci. Technol. 48, 1108-1114 (2011).

5. Pierce, E. M. et al. Integrated Disposal Facility FY2010 Glass Testing Summary Report. PNNL - 19736. U.S. Department of Energy. https://www.pnnl.gov/main/ publications/external/technical_reports/PNNL-19736.pdf (2020).

6. Bingham, P. A., Connelly, A. J., Hand, R. J. \& Hyatt, N. C. Vitrification of UK intermediate level radioactive wastes arising from site decommissioning: property modelling and selection of candidate host glass compositions. Glass Technol.: Eur. J. Glass Sci. Technol. Part A 53, 83-100 (2012).

7. THERAMIN, 2019, Thermal treatment for radioactive waste minimization and hazard reduction. http://www.theramin-h2020.eu/ (2021).

8. PREDIS (Pre-disposal management of radioactive waste). https://predis-h2020. eu/predis-project/ (2020).

9. Walling, S. A. et al. Characterisation and disposability assessment of multi-waste stream in-container vitrified products for higher activity radioactive waste. $J$. Hazard. Mater. 401, 123764 (2021).

10. Hyatt, N. C. \& James, M. Thermal treatment of ILW. Nucl. Eng. Inter. 58, 10-13 (2013).

11. Hyatt, N. C. et al. Thermal treatment of simulant plutonium contaminated materials from the Sellafield site by vitrification in a blast-furnace slag. J. Nucl. Mater. 444, 186-199 (2014).

12. Tan, S., Kirk, N., Marshall, M., McGann, O. \& Hand, R. J. Vitrification of an intermediate level Magnox sludge waste. J. Nucl. Mater. 515, 392-400 (2019).

13. Harnett, L. C., Gardner, L. J., Sun, S., Mann, C. \& Hyatt, N. C. Reactive spark plasma sintering of Cs-exchanged chabazite: characterisation and durability assessment for Fukushima Daiichi NPP clean-up. J. Nucl. Sci. Technol. 56, 891-901 (2019).

14. McGrail, B. P., Bacon, D. H., Serne, R. J. \& Pierce, E. M. A Strategy to Assess Performance of Selected Low-activity Waste Forms in An Integrated Disposal Facility. PNNL-14362 (Pacific Northwest National Laboratory, 2003).

15. Goel, A., McCloy, J. S., Pokorny, R. \& Kruger, A. A. Challenges with vitrification of Hanford high-level waste (HLW) to borosilicate glass-an overview. J. Non-Cryst. Solids .: X 4, 100033 (2019).

16. Kim, C. \& Day, D. E. Immobilization of Hanford LAW in iron phosphate glasses. J. Non-Cryst. Solids 331, 20-31 (2003).
17. Brow, R. K., Kim, C. W. \& Reis, S. T. Iron polyphosphate glasses for waste immobilization. Int. J. Appl. Glass Sci. 11, 4-14 (2020).

18. IAEA. Geological Disposal Facilities for Radioactive Waste. IAEA Safety Standard Series, No. SSG-14. https://www-pub.iaea.org/MTCD/Publications/PDF/ Pub1483_web.pdf (2011).

19. IAEA. Scientific and Technical Basis for the Geological Disposal of Radioactive Wastes. Technical report series, No. 413, (IAEA, 2003).

20. IAEA. Performance of Engineered Barrier Materials in Near Surface Disposal Facilities for Radioactive Waste (IAEA, 2001).

21. Corkhill, C. L. \& Hyatt, N. C. Nuclear Waste Management. Physics World Discovery (IOP Publishing, 2018).

22. Harrison, M. T. Review of glass dissolution rates for use in the disposal system safety case performance assessment models. NNL 10, 10734 (2010).

23. Kim, M. et al. Leaching behaviors and mechanisms of vitrified forms for the lowlevel radioactive solid wastes. J. Hazard. Mater. 384, 121296 (2020).

24. National Research Council. Waste Forms Technology and Performance: Final Report (The National Academies Press, 2011).

25. Strachan, D. M. Glass dissoltion: testing and modeling for long-term behaviour. J. Nucl. Mater. 298, 69-77 (2001).

26. Inagaki, Y. Microchannel as a tool to investigate glass dissolution kinetics. Proc. Mat. Sci. 7, 172-178 (2014).

27. Fournier, M. et al. Glass dissolution rate measurement and calculation revisited. J. Nucl. Mat. 476, 140-154 (2016).

28. Varshneya, A. K. \& Mauro, J. C. Fundamentals of Inorganic Glasses, third edn. (Elsevier, 2019).

29. Ojovan, M. I., Lee, W. E. \& Kalmykov, S. N. (eds). Performance of wasteform materials. In An Introduction to Nuclear Waste Immobilisation, third edn. Ch. 23, 433-461 (Elsevier, 2019).

30. Strachan, D. Glass dissolution as a function of $\mathrm{pH}$ and its implications for understanding mechanisms and future experiments. Geochim. Cosmochim. Acta 219, 111-123 (2017).

31. Gin, S., Frugier, P., Jollivet, P. \& Bruguier, F. New insight into the residual rate of borosilicate glasses: effect of S/N and glass composition. Int. J. Appl. Glass Sci. 4, 371-382 (2013).

32. Frugier, P. et al. SON68 nuclear glass dissolution kinetics: current state of knowledge and basis of the new GRAAL model. J. Nucl. Mater. 380, 8-21 (2008).

33. Gin, S. et al. Origin and consequences of silicate glass passivation by surface layers. Nat. Commun. 6, 8 (2015).

34. Bunker, B. C. Molecular mechanisms for corrosion of silica and silicate glasses. J. Non-Cryst. Solids 179, 300-308 (1994).

35. Grambow, B. A general rate equation for nuclear waste glass corrosion, in Scientific Basis for Nuclear Waste Management VIII, edited by Jantzen, C., Stone, J. and Ewing, R. Mat. Res. Soc. Proc. 44, 15-24 (1984).

36. Van Iseghem, P. et al. Glamor- or how we achieved a common understanding on the decrease of glass dissolution kinetics through international cooperation. J. South Carol. Acad. Sci. 9, 6 (2011).

37. Fournier, M., Gin, S. \& Frugier, P. Resumption of nuclear glass alteration: state of the art. J. Nucl. Mater. 448, 348-363 (2014).

38. Gin, S. Insights into the mechanisms controlling the residual corrosion rate of borosilicate glasses. npj Mater. Degrad. 4, 41 (2020).

39. Ojovan, M. I., Pankov, A. S. \& Lee, W. E. The ion exchange phase in corrosion of nuclear waste glasses. J. Nucl. Mater. 358, 57-68 (2006).

40. Gin, S. Atom-probe tomography, TEM and ToF-SIMS study of borosilicate glass alteration rim: a multiscale approach to investigating rate-limiting mechanisms. Geochim. Cosmochim. Acta, 202, 57-76 (2017).

41. Geisler, T. et al. The mechanism of borosilicate glass corrosion revisited. Geochim. Cosmochim. Acta 158, 112-129 (2015).

42. Geisler, T. et al. Aqueous corrosion of borosilicate glass under acidic conditions: a new corrosion mechanism. J. Non-Cryst. Solids 356, 1458-1465 (2010).

43. Van Iseghem, P. \& Grambow, B. The long-term corrosion and modelling of two simulated Belgian reference high-level waste glasses. In Scientific Basis for Nuclear Waste. (eds Apted, M. J. \& Westerman, R. E.) p. 631 (MRS Proceedings, Cambridge University Press, 1988). https://doi.org/10.1557/PROC-112-631.

44. Strachan, D. M. \& Croak, T. L. Compositional effects on long-term dissolution of borosilicate glass. J. Non-Crystalline Solids 272, 22-33 (2000).

45. Strachan, D. M. \& Neeway, J. J. Effects of alteration product precipitation on glass dissolution. Appl. Geochem. 45, 144-157 (2014).

46. Fournier, $\mathrm{M}$. et al. Effect of $\mathrm{pH}$ on the stability of passivating gel layers formed on International Simple Glass. J. Nucl. Mater. 524, 21-38 (2019).

47. Mercado-Depierre, S., Fournier, M., Gin, S. \& Angeli, F. Influence of zeolite precipitation on borosilicate glass alteration under hyperalkaline conditions. J. Nucl. Mater. 491, 67-82 (2017).

48. Ojovan, M. On alteration rate renewal stage of nuclear waste glass corrosion. MRS Adv. 5, 111-120 (2020). 
49. Majérus, O. et al. Glass alteration in atmospheric conditions: crossing perspectives from cultural heritage, glass industry, and nuclear waste management. $n p j$ Mater. Degrad. 4, 27 (2020).

50. Alternative Waste Form Peer Review Panel. The Evaluation and Review of Alternative Waste Forms for Immobilization of High-level Radioactive Wastes. Report number 2, DOE/TIC-11219 (United States Department of Energy, 1980).

51. Bernadzikowski, T. A. The Evaluation and Selection of Candidate High Level Waste Forms. USDOE/TIC-11611 (National Technical Info. Service, 1982).

52. Interface Working Group on High-Level Waste Form Selection Factors. A Method for Product Performance Evaluation of Candidate Waste Forms for Immobilization of High-level Radioactive Wastes. DOG/TIC-1 1612 (United States Department of Energy, 1982).

53. Hespe, E. D. Leach testing of immobilized radioactive waste solids. Atomic Energy Rev. 9, 195-207 (1971).

54. MCC, Material Characterization Center. Nuclear Waste Materials Handbook. DOE/ TIC 11400 (Pacific Northwest National Laboratory, 1981).

55. Abdelouas, A. et al. A preliminary investigation of the ISG glass vapour hydration. Int. J. Appl. Glass Sci. 4, 207-316 (2013).

56. Chinnam, R. K., Fossati, P. C. M. \& Lee, W. E. Degradation of partially immersed glass: a new perspective. J. Nucl. Mater. 503, 56-65 (2018)

57. McGrail, B. P., Ebert, W. L., Bakel, A. L. \& Peeler, D. K. Measurement of kinetic rate law parameters on a $\mathrm{Na}$.Ca.Al borosilicate glass for low-activity waste. J. Nucl. Mater. 249, 175-189 (1997).

58. Inagaki, Y. et al. Initial dissolution rate of a Japanese simulated high-level waste glass $\mathrm{P} 0798$ as a function of $\mathrm{pH}$ and temperature measured by using microchannel flow-through test method. J. Nucl. Sci. Technol. 49, 438-449 (2012).

59. Neeway, J. J., Rieke, P. C., Parruzot, B. P., Ryan, J. V. \& Asmussen, R. M. The dissolution behavior of borosilicate glasses in far-from equilibrium conditions. Geochim. Cosmochim. Acta 226, 132-148 (2018).

60. Vienna, J. D., Neeway, J. J., Ryan, J. V. \& Kerisit, S. N. Impacts of glass composition, $\mathrm{pH}$, and temperature on glass forward dissolution rate. npj Mater. Degrad. 2, 22 (2018).

61. Inagaki, Y., Kikunaga, T., Idemitsu, K. \& Arima, T. Initial dissolution rate of the International Simple Glass as a function of $\mathrm{pH}$ and temperature measured by using micro-channel flow-through test method. Int. J. Appl. Glass Sci. 4, 317-327 (2013).

62. Icenhower, J. \& Dove, P. M. The dissolution kinetics of amorphous silica into sodium chloride solutions: effects of temperature and ionic strength. Geochim. Cosmochim. Acta 64, 4193-4203 (2000).

63. Wolff-Boenisch, D., Gislason, S. R., Oelkers, E. H. \& Putnis, C. V. The dissolution rates of natural glasses as a function of their composition at $\mathrm{pH} 4$ and 10.6, and temperatures from 25 to $74^{\circ} \mathrm{C}$. Geochim. Cosmochim. Acta $68,4843-4858$ (2004).

64. Criscenti, L. J., Kubicki, J. D. \& Brantley, S. L. Silicate glass and mineral dissolution: calculated reaction paths and activation energies for hydrolysis of a $\mathrm{Q}^{3} \mathrm{Si}$ by $\mathrm{H}_{3} \mathrm{O}^{+}$using ab initio methods. J. Phys. Chem. A. 110, 198-206 (2006).

65. McGrail, B. P. \& Olson, K. M. Evaluating Long-term Performance of In-situ Vitrified Waste Forms: Methodology and Results. PNL-8358 (Pacific Northwest National Laboratory, 1992).

66. McGrail, B. P. \& Peeler, D. K. Evaluation of the Single-pass Flow-through Test to Support a Low-activity Waste Specification. PNL-10746 (Pacific Northwest National Laboratory, 1995).

67. ASTM C1662, Standard Practice for Measurement of the Glass Dissolution Rate Using the Single-Pass Flow-Through Test Method, ASTM C1662 (2018).

68. Caes, S., Ferrand, K. \& Lemmens, K. Topical report on dynamic dissolution test on SON68, SM513, SM539 and ISG glasses. Sck.cen Report. SCK CEN/37731394, Revision 1. https://publications.sckcen.be/portal/files/6978728/ResearchOutput37731394.pdf (2020)

69. Cassingham, N. et al. The initial dissolution rates of simulated UK MagnoxThORP blend nuclear waste glass as a function of $\mathrm{pH}$, temperature and waste loading. Mineral. Mag. 79, 1529-1542 (2015).

70. Corkhill, C. L., Fisher, A. J., Strachan, D. M., Hand, R. J. \& Hyatt, N. C. Corrigendum to 'The initial dissolution rates of simulated UK Magnox-ThORP blend nuclear waste glass as a function of $\mathrm{pH}$, temperature and waste loading' (Mineralogy Mag. 79, 1529-1542 (2015)). Mineral. Mag. 82, 939-942 (2018).

71. Backhouse, D. J. et al. Corrosion of the International Simple Glass under acidic to hyperalkaline conditions. npj Mater. Degrad. 2, 29 (2018).

72. Iwalewa, T. M., Qu, T. \& Farnan, I. Investigation of the maximum dissolution rates and temperature dependence of a simulated UK nuclear waste glass in circumneutral media at 40 and $90^{\circ} \mathrm{C}$ in a dynamic system. Appl. Geochem. 82, 177-190 (2017).

73. Hellmann, R. et al. Nanometer-scale evidence for interfacial dissolutionreprecipitation control of silicate glass corrosion. Nat. Mater. 14, 307-311 (2015)

74. Geisler, T., Dohmen, L., Lenting, C. \& Fritzsche, M. B. K. Real-time in situ observations of reaction and transport phenomena during silicate glass corrosion by fluid-cell Raman spectroscopy. Nat. Mater. 18, 342-348 (2019).
75. Fisher, A. J., Hyatt, N. C., Hand, R. J. \& Corkhill, C. L. The formation of pitted features on the International Simple Glass during dynamic experiments at alkaline pH. MRS Adv. 4, 993-999 (2019).

76. Delage, F. \& Dussossoy, J. L. R7T7 glass initial dissolution rate measurements using a high-temperature soxhlet device. MRS Online Proc. Libr. 212, 41-47 (1990).

77. Crum, J. V. et al. Dilute condition corrosion behavior of glass-ceramic waste form. J. Nucl. Mater. 482, 1-11 (2016).

78. ASTM C1285. Standard Test Methods for Determining the Chemical Durability of Nuclear Waste Glasses: The Product Consistency Test (PCT). ASTM C1285-21 (ASTM, 2014).

79. Ebert, W. L. \& Wolf, S. F. An interlaboratory study of a standard glass for acceptance testing of low-activity waste glass. J. Nucl. Mater. 282, 112-124 (2000).

80. ASTM C1220. Standard Test Method for Static Leaching of Monolithic Waste Forms for Disposal of Radioactive Waste. ASTM C1220-17 (ASTM, 2017).

81. Jantzen, C. M. \& Bibler, N. E. The product consistency test (PCT): how and why it was developed? Ceram. Trans. 207, 155-167 (2009).

82. Ebert, W. L., Bates, J. K., Buck, E. C. \& Bradley, C. R. Accelerated glass reaction under PCT conditions. Mater. Res. Soc. Symp. Proc. 294, 569-576 (1993).

83. Aréna, H., Rébiscoul, D., Garcès, E. \& Godon, N. Comparative effect of alkaline elements and calcium on alteration of International Simple Glass. npj Mater. Degrad. 3, 10 (2019).

84. Utton, C. A. et al. Dissolution of vitrified wastes in a high-pH calcium-rich solution. J. Nucl. Mater. 435, 112-122 (2013).

85. Schofield, J. M. et al. Experimental studies of the chemical durability of UK HLW and ILW glasses - interim progress report (AMEC/103498/IPR/02 revision 3) Available at: https://rwm.nda.gov.uk/publication/experimental-studies-of-thechemical-durability-of-uk-hlw-and-ilw-glasses-interim-progress-reportamec103498ipr02-revision-3/ (2017).

86. Vernaz, E., Advocat, T. \& Dussossoy, J. L. Effects of the SA/V ratio on the longterm corrosion kinetics of R7T7 glass. Ceram. Trans. 9, 175-185 (1990)

87. Ebert, W. L. The Effects of the Glass Surface Area/solution Volume Ratio on Glass Corrosion: A Critical Review. ANL-94/34. (Chemical Technical Division, Argonne National Laboratory, 1995).

88. ASTM C1663. Standard Test Method for Measuring Waste Glass or Glass Ceramic Durability by Vapor Hydration Test. ASTM C1663-18 (ASTM, 2018).

89. PNNL. Pacific Northwest National Laboratory, Vapor-phase Hydration Test Procedure. GDL-VHT, Rev.1 (Pacific Northwest National Laboratory, 1999).

90. Bouakkaz, R., Abdelouas, A. \& Grambow, B. Kinetic study and structural evolution of SON68 nuclear waste glass altered from 35 to $125^{\circ} \mathrm{C}$ under unsaturated $\mathrm{H}_{2} \mathrm{O}$ and $\mathrm{D}_{2} \mathrm{O}^{18}$ vapour conditions. Corros. Sci. 134, 1-16 (2018).

91. Narayanasamya, S. et al. Influence of composition of nuclear waste glasses on vapor phase hydration. J. Nucl. Mater. 525, 53-71 (2019).

92. Narayanasamy, S., Jollivet, P., Sessegolo, L., Angeli, F. \& Abdelouas, A. Influence of temperature and relative humidity on vapor hydration of an AVM nuclear waste glass. J. Nucl. Mater. 543, 152571 (2021).

93. ANDRA, Dossier 2005 Argile, Tome, Phenomenological Evolution of a Geological Repository, in ANDRA Report C.RP.ADS.04.0025, 1-525 (ANDRA, 2005).

94. Neeway, J. Vapor hydration of SON68 glass from 90 C to $200 \mathrm{C}$ : a kinetic study and corrosion products investigation. J. Non-Cryst. Solids 358, 2894-2905 (2012).

95. Debure, M., De Windt, L., Frugier, P., Gin, S. \& Vieillard, P. Mineralogy and thermodynamic properties of magnesium phyllosilicates formed during the alteration of a simplified nuclear glass. J. Nucl. Mater. 475, 255-265 (2016)

96. Bouakkaz, R., Abdelouas, A., El Mendili, Y., David, K. \& Grambow, B. Alteration of 29Si-doped SON68 borosilicate nuclear waste glass in the presence of near field materials. Appl. Geochem. 111, 104436 (2019)

97. De Echave, T., Tribet, M., Gin, S. \& Jégou, C. Influence of iron on the alteration of the SON68 nuclear glass in the Callovo-Oxfordian groundwater. Appl. Geochem. 100, 268-278 (2019).

98. EPA SW-846. Validated Test Method 1313: Liquid-Solid Partitioning as a Function of Extract pH Using a Parallel Batch Extraction Procedure, Environmental Protection Agency. https://www.epa.gov/hw-sw846/validated-testmethod-1313-liquid-solidpartitioning-function-extract-ph-using-parallel (2017).

99. Thorpe, C. L. et al. Evaluation of Novel Leaching Assessment for Nuclear Waste Glasses - 18314. WM2018 Conference, March 18-22 (Phoenix, Arizona, USA, 2018).

100. EPA SW-846. Test Method 1311: Toxicity Characteristic Leaching Procedure, part of Test Methods for Evaluating Solid Waste, Physical/Chemical Methods. (Environmental Protection Agency, 1992).

101. ANS - 16.1. Measurement of the Leachability of Solidified Low Level Radioactive Wastes by a Short-Term Test Procedure. (American National Standard Institute, 2019).

102. International Organization for Standardization. ISO 6961:1982(E): Long-Term Leach Testing of Solidified Radioactive Waste Forms (1982). 
103. EPA SW-846. Validated Test Method 1315: Mass Transfer Rates of Constituents in Monolithic or Compacted Granular Materials Using a Semi-Dynamic Tank Leaching Procedure. (Environmental Protection Agency, 2017).

104. Singh, D., Mandalika, V. R., Parulekar, S. J. \& Wagh, A. S. Magnesium potassium phosphate ceramic for 99Tc immobilization. J. Nucl. Mater. 348, 272-282 (2006).

105. ASTM C1308. Standard Test Method for Accelerated Leach Test for Diffusive Releases from Solidified Waste and a Computer Program to Model Diffusive, Fractional Leaching from Cylindrical Waste Forms. ASTM C1308-08 (ASTM, 2017).

106. Ebert, W. L. \& Fortner, J. A. Analyses of iron phosphate glasses for dehalogenated salt waste. Report number ANL/CFCT-19/5 153602 (ANL, 2019).

107. Nam, J., Chong, S., Riley, B. J. \& McCloy, J. S. lodosodalite waste forms from lowtemperature aqueous process. MRS Adv. 3, 1093-1103 (2018).

108. Chong, S. et al. Glass-bonded iodosodalite waste form for immobilization of 129l. J. Nucl. Mater. 504, 109-121 (2018)

109. Pierce, E. M., McGrail, B. P., Valenta, M. M. \& Strachan, D. M. The accelerated weathering of a radioactive low-activity waste glass under hydraulically unsaturated conditions: experimental results from a pressurized unsaturated flow (PUF) test. Nucl. Technol. 155, 133-148 (2006).

110. Pierce, E. M. et al. Accelerated weathering of high-level and plutonium-bearing lanthanide borosilicate waste glasses under hydraulically unsaturated conditions. Appl. Geochem. 22, 1841-1859 (2007).

111. Neeway, J. J. et al. Performance of the Fluidized Bed Steam Reforming product under hydraulically unsaturated conditions. J. Environ. Radioact. 313, 119-128 (2014).

112. McGrail, B. P., Lindenmeier, C. W., Martin, P. F. \& Gee, G. W. The pressurized unsaturated flow (PUF) test: a new method for engineered-barrier materials evaluation. Environ. Issues Waste Manag. Technol. Ceram. Nucl. Industries II 72, 17-329 (1996).

113. Heierli, J. \& Genoni, O. The role of temperature in the safety case for high-level radioactive waste disposal: a comparison of design concepts. Geosciences 7, 42 (2017).

114. Ojovan, M. I. \& Lee, W. E. About U-shaped glass corrosion rate/pH curves for vitreous nuclear wasteforms. Innov. Corros. Mater. Sci. 7, 30-37 (2017).

115. Krauskopf, K. B. Dissolution and precipitation of silica at low temperatures. Geochem. Cosmochim. Acta 10, 1-26 (1956).

116. Franke, W. A. The durability of rocks-developing a test of rock resistance to chemical weathering. Am. J. Sci. 309, 711-730 (2009).

117. Mann, C. et al. Influence of young cement water on the corrosion of the International Simple Glass. npj Mater. Degrad. 3, 5 (2019).

118. Elia, A., Ferrand, K. \& Lemmens, K. Determination of the forward dissolution rate for international simple glass in alkaline solutions. MRS Adv. 2, 611-667 (2017).

119. Van Iseghem, P., Valcke, E., Godon, N. \& Jockwer, N. CORALUS: an integrated in situ corrosion test on a-active glass. MRS Proc. 506, 961 (1997).

120. Dillmann, P., Gin, S., Neff, D., Gentaz, L. \& Rebiscoul, D. Effect of natural and synthetic iron corrosion products on silicate glass alteration processes. Geochim. Cosmochim. Acta 172, 287-305 (2016).

121. Frugier, P., Chave, T., Gin, S. \& Lartigue, J. E. Application of the GRAAL model to leaching experiments with SON68 nuclear glass in initially pure water. J. Nucl. Mater. 392, 552-567 (2009).

122. Scheetz, B. E. et al. The role of boron in monitoring the leaching of borosilicate glass waste forms. MRS Proc. 44, 129 (1984).

123. Icenhower, J. P. Results of vertical scanning interferometry (VSI) of dissolved borosilicate glass: evidence for variable surface features and global surface retreat. MRS Proc. 757, 115 (2002).

124. Icenhower, J. P. \& Steefel, C. I. Dissolution rate of borosilicate glass SON68: a method of quantification based upon interferometry and implications for experimental and natural weathering rates of glass. Geochim. Cosmochim. Acta 157, 147-163 (2015)

125. Lüttge, A. \& Arvidson, R. S. Reaction at surfaces: a new approach integrating interferometry and kinetic simulations. J. Am. Ceram. Soc. 93, 3519-3530 (2010).

126. Icenhower, J. P. \& Steefel, C. I. Experimentally determined dissolution kinetics of SON68 glass at $90^{\circ} \mathrm{C}$ over a silica saturation interval: evidence against a linear rate law. J. Nucl. Mater. 439, 137-147 (2013)

127. Dussossoy, J. L., Dubois, C., Vernaz, E. \& Chambaudet, A. Effect of surface finish on nuclear glass dissolution rate. MRS Proc. 257, 109 (1991).

128. Jiřička, A., Vienna, J. D., Hrma, P. \& Strachan, D. M. The effect of experimental conditions and evaluation techniques on the alteration of low activity glasses by vapor hydration. J. Non-Cryst. Solids 292, 25-43 (2001).

129. Liu, H., Ngo, D., Ren, M., Du, J. \& Kim, S. H. Effects of surface initial condition on aqueous corrosion of glass-a study with a model nuclear waste glass. J. Am. Cer. Soc. 102, 1652-1664 (2019).

130. Sessegolo, L., Verney-Carron, A., Ausset, P., Saheb, M. \& Chabas, A. Effect of surface roughness on medieval-type glass alteration in aqueous medium. $J$. Non-Cryst. Solids 505, 260-271 (2019).
131. Neeway, J. J. et al. lon-exchange interdiffusion model with potential application to long-term nuclear waste glass performance. J. Phys. Chem. C. 120, 9374-9384 (2016).

132. Kirste, G. et al. Effect of chloride ions in Tris buffer solution on bioactive glass apatite mineralization. Int. J. Appl. Glass Sci. 8, 438-449 (2017).

133. Xing, S. B. \& Pegg, I. G. Effects of container material on PCT leach test results for high-level nuclear waste glasses. MRS Proc. 333, 557-564 (1994).

134. McCloy, J. S., Schweiger, M. J., Rodriguez, C. P. \& Vienna, J. D. Nepheline crystallization in nuclear waste glasses: progress toward acceptance of high-alumina formulations. Int. J. Appl. Glass Sci. 2, 201-214 (2011).

135. Marcial, J., Crum, J., Neill, O. \& McCloy, J. Nepheline structural and chemical dependence on melt composition. Am. Mineral. 101, 266-276 (2016).

136. Gardner, L. J., Walling, S. A., Corkhill, C. L. \& Hyatt, N. C. Thermal treatment of Csexchanged chabazite by hot isostatic pressing to support decommissioning of Fukushima Daiichi Nuclear Power Plant. J. Hazard. Mater. 413, 125250 (2021).

137. Icenhower, J. P. et al. Experimentally determined dissolution kinetics of Na-rich borosilicate glass at far from equilibrium conditions: implications for transition state theory. Geochim. Cosmochim. Acta 72, 2767-2788 (2008).

138. Jantzen, C. M., Brown, K. G. \& Pickett, J. B. Durable glass for thousands of years. Int. J. Appl. Glass Sci. 1, 38-62 (2010).

139. Pierce, E. M. et al. Experimental determination of the effect of the ratio of $B / A I$ on glass dissolution along the nepheline $\left(\mathrm{NaAlSiO}_{4}\right)$-malinkoite $\left(\mathrm{NaBSiO}_{4}\right)$ join. Geochim. Cosmochim. Acta 74, 2634-2654 (2010).

140. Asmussen, R. M., Neeway, J. J., Kaspar, T. C. \& Crum, J. V. Corrosion behavior and microstructure influence of glass-ceramic nuclear waste forms. Corrosion 73, 1306-1319 (2017).

141. Fox, M. K., Edwards, T. B. \& Peeler, D. K. Control of nepheline crystallization in nuclear waste glass. Int. J. Appl. Ceram. Technol. 5, 666-673 (2008).

142. Jantzen, C. M. \& Trivelpiece, C. L. Uranium dissolution and geochemical modeling in anoxic and oxic solutions. MRS Adv. 2, 705-710 (2017).

143. Boast, L. Investigation of The Thermal Treatment of Higher Activity Waste. Thesis, University of Sheffield (2018).

144. Jantzen, C. M., Bibler, N. E., Beam, D. C., Crawford, C. L. \& Pickett, M. A. Characterisation of the Waste Processing Facility (DWPF) Environmental Assessment (EA) Glass Standard Reference Material. Report: WSRC-TR-92-346, US DOE. 10.2172/10173249 (1993).

145. Gin, S. et al. An international initiative on long-term behaviour of high-level nuclear waste glass. Mater. Today 16, 243-248 (2013).

146. Kaspar, T. C. et al. Physical and optical properties of the International Simple Glass. npj Mater. Degrad. 3, 15 (2019).

147. SRNL. Letter Report on Compositional Measurements of Common Simple Glass. Savannah River National Laboratory, SRNL-L3100-2012-00092 (SRNL, 2012).

148. Aréna, $\mathrm{H}$. et al. Impact of $\mathrm{Zn}, \mathrm{Mg}, \mathrm{Ni}$ and $\mathrm{Co}$ elements on glass alteration: additive effects. J. Nucl. Mater. 470, 55-67 (2016).

149. Aréna, $H$. et al. Impact of iron and magnesium on glass alteration: characterization of the secondary phases and determination of their solubility constants. Appl. Geochem. 82, 119-133 (2017).

150. Aréna, $\mathrm{H}$. et al. Impact of $\mathrm{Fe}, \mathrm{Mg}$ and $\mathrm{Ca}$ elements on glass alteration: interconnected processes. Geochim. Cosmochim. Acta 239, 420-445 (2018).

151. Collin, M. et al. Structure of International Simple Glass and properties of passivating layer formed in circumneutral $\mathrm{pH}$ conditions. npj Mater. Degrad. 2, 4 (2018).

152. Reiser, J. T. et al. Effects of $\mathrm{Al}: \mathrm{Si}$ and $(\mathrm{Al}+\mathrm{Na}): \mathrm{Si}$ ratios on the static corrosion of sodium-boroaluminosilicate glasses. Int. J. Appl. Glass Sci. https://doi.org/ 10.1111/ijag.16109 (2020)

153. Rieke, P. C. \& Kerisit, S. N. Modelling Tool Enhancement. PNNL-25111 (Pacific Northwest National Laboratory, 2016).

154. Gin, S. et al. The fate of silicon during glass corrosion under alkaline conditions: a mechanistic and kinetic study with the International Simple Glass. Geochim. Cosmochim. Acta 151, 68-85 (2015).

155. Fournier, M., Gin, S., Frugier, P. \& Mercado-Depierre, S. Contribution of zeoliteseeded experiments to the understanding of resumption of glass alteration. $n p j$ Mater. Degrad. 1, 17 (2017).

156. Collin, M. et al. ToF-SIMS depth profiling of altered glass. npj Mater. Degrad. 3, 14 (2019).

157. Morss, L. R., Lewis, M. A., Richmann, M. K. \& Lexa, D. Cerium, uranium, and plutonium behavior in glass-bonded sodalite, a ceramic nuclear waste form. J. Alloy. Compd. 303-304, 42-48 (2000).

158. Icenhower, J. P. et al. Dissolution kinetics of pyrochlore ceramics for the disposition of plutonium. Am. Mineral. 91, 39-53 (2006).

159. Barlow, S. T. et al. Thermal treatment of nuclear fuel-containing Magnox sludge radioactive waste. J. Nucl. Mater. 552, 152965 (2021).

160. Hyatt, N. C., Morgan, S., Stennett, M. C., Scales, C. R. \& Deegan, D. Plasma vitrification of waste plutonium contaminated materials. MRS Proc. 985, 393-398 (2007). 
161. Bingham, P., Hyatt, N. C. \& Hand, R. J. Vitrification of UK intermediate level radioactive wastes arising from site decommissioning: property modelling and selection of candidate host glass compositions. Glass Technol. 53, 83-100 (2012).

162. Witwer, K., Woosley, S. Campbell, B. Wong, M. \& Hill, J. GeoMeltR ICVTM Treatment of Sellafield Pond Solids Waste - 13414. Waste Management 2013 WM2013 Conference: International collaboration and continuous improvement (United States, 2013).

163. Lutze, W., Grambow, B., Ewing, R. C. \& Jercinovic, M. J. The Use of Natural Analogues in the Long-term Extrapolation of Glass Corrosion Processes. In Natural Analogues in Radioactive Waste Disposal (eds Côme, B. \& Chapman, N. A.). 142-152 (Springer, 1987).

164. Miller, W., Alexander, R., Chapman, N. \& McKinley, J. Geological Disposal of Radioactive Wastes and Natural Analogues. Vol. 2 (Elsevier, 2000).

165. Verney-Carron, A., Gin, S. \& Libourel, G. Archaeological analogs and the future of nuclear waste glass. J. Nucl. Mater. 406, 365-370 (2010).

166. Libourel, G. et al. The use of natural and archeological analogues for understanding the long-term behavior of nuclear glasses. Comptes Rendus Geosci. 343, 237-245 (2011).

167. McCloy, J. S. Frontiers in natural and un-natural glasses: an interdisciplinary dialogue and review. J. Non-Cryst. Solids.: X 4, 100035 (2019).

168. Crovisier, J. L., Advocat, T. \& Dussossoy, J. L. Nature and role of natural alteration gels formed on the surface of ancient volcanic glasses (natural analogs of waste containment glasses). J. Nucl. Mater. 321, 91-109 (2003).

169. Parruzot, B. et al. Multi-glass investigation of Stage III glass dissolution behavior from 22 to $90^{\circ} \mathrm{C}$ triggered by the addition of zeolite phases. J. Nucl. Mater. 523, 490-501 (2019).

170. Verney-Carron, A., Gin, S. \& Libourel, G. A fractured roman glass block altered for 1800 years in seawater: analogy with nuclear waste glass in a deep geological repository. Geochim. Cosmochim. Acta 72, 5372-5385 (2008).

171. Weaver, J. L. et al. Pre-viking Swedish hillfort glass: a prospective long-term alteration analogue for vitrified nuclear waste. Int. J. Appl. Glass Sci. 9, 540-554 (2018).

172. Ahmadzadeh, M., García-Lasanta, C., Housen, B. \& McCloy, J. S. Archaeomagnetic dating of vitrified Bröborg hillfort in southeast Uppsala, Sweden. J. Archaeo. Sci.: Rep. 31, 102311 (2020).

173. Plymale, A. E. et al. Niche partitioning of microbial communities at an ancient vitrified hillfort: implications for vitrified radioactive waste disposal. Geomicro. J. 38, 36-56 (2021).

174. McGrail, B. P. Waste package component interactions with savannah river defense waste glass in a low-magnesium salt brine. Nucl. Technol. 75, 168-186 (1986).

175. Wicks, G. G., Lodding, A. R., Macedo, P. B., Clark, D. E. \& Molecke, M. A. MIIT: International in-situ testing of simulated HLW forms-preliminary analyses of SRL 165/ TDS waste glass and metal systems. Conference: 1. international topical meeting on high-level radioactive waste management, Las Vegas, NV (United States), 8-12 Apr 1990. https://www.osti.gov/biblio/5566741-miit-international-situ-testing-simulatedhlw-forms-preliminary-analyses-srl-tds-waste-glass-metal-systems (OSTI, 1990).

176. Williams, J. P., Wicks, G. G., Clark, D. E. \& Lodding, A. R. Analyses of SRS waste glass buried in granite in Sweden and salt in the United States (U). American Ceramic Society Fifth International Symposium on Ceramics in Nuclear and Hazardous Waste Management, WSRC-MS-90-370 (1991).

177. Jantzen, C. M., Kaplan, D. I., Bibler, N. E., Peeler, D. K. \& Plodinec, M. J. Performance of a buried radioactive high level waste (HLW) glass after 24 years. J. Nucl. Mater. 378, 244-256 (2008).

178. Ojovan, N. V. et al. Secondary phases on the surface of real vitrified radioactive waste disposed in a loamy soil. MRS Proc. 807, 712-717 (2004).

179. Fletcher, W. W. The chemical durability of glass. A burial experiment at Ballidon in Derbyshire. J. Glass Stud. 14, 149-151 (1972).

180. McLoughlin, S. D., Hand, R. J., Hyatt, N. C. \& Lee, W. E. The long term corrosion of glasses: analytical results after 32 years of burial at Ballidon. Glass Technol. - Eur. J. Glass Sci. Technol. Part A 47, 59-67 (2006).

181. Mann, C. et al. Interactions between simulant vitrified nuclear wastes and high pH solutions: a natural analogue approach. MRS Adv. 2, 667-674 (2017).

182. Bacon, D. et al. Field-Scale Lysimeter Studies of Low-Activity Waste Form Degradation. PNNL-27394; RPT-IGTP-017 (Pacific Northwest National Laboratory, 2018).

183. Van Iseghem, P., Valcke, E. \& Lodding, A. In situ testing of the chemical durability of vitrified high-level waste in a Boom Clay formation in Belgium: discussion of recent data and concept of a new test. J. Nucl. Mater. 298, 86-94 (2001).

184. Lemmens, K. \& Van Iseghem, P. The effect of gamma radiation on the dissolution of high-level waste glass in boom clay. MRS Proc. 663, 175-182 (2001).

185. Peuget, S., Tribet, M., Mougnaud, S., Miro, S. \& Jégou, C. Radiations effects in ISG glass: from structural changes to long-term aqueous behavior. npj Mater. Degrad. 2, 23 (2018).
186. Zubekhina, B. Y. et al. Chemical alteration of 238Pu-loaded borosilicate glass under saturated leaching conditions. Radiochim. Acta 108, 19-27 (2020).

187. Zubekhina, B. Y., Burakov, B. E. \& Ojovan, M. I. Surface alteration of borosilicate and phosphate nuclear waste glasses by hydration and irradiation. Challenges 2020 11, 14 (2020).

188. Tribet, $M$. et al. Alpha dose rate and decay dose impacts on the long-term alteration of HLW nuclear glasses. npj Mater. Degrad. 5, 36 (2021).

189. Rolland, S. et al. Influence of gamma irradiation effects on the residual alteration rate of the French SON68 nuclear glass. J. Nucl. Mater. 433, 382-389 (2013).

190. Rolland, S. et al. 99Tc- and 239Pu-doped glass leaching experiments: residual alteration rate and radionuclide behavior. Int. J. Appl. Glass Sci. 4, 295-306 (2013).

191. IAEA. The Safety Case and Safety Assessment for the Disposal of Radioactive Waste. IAEA Safety Standards Series No. SSG-23 (IAEA, 2012).

192. THERAMIN. Deliverable Report. Synthesis report of WP4. http://www.theraminh2020.eu/downloads/THERAMIN\%20D4_4\%20Synthesis\%20report\%20of\% 20WP4.pdf (2020).

193. Fournier, M., Frugier, P. \& Gin, S. Application of GRAAL model to the resumption of International Simple Glass alteration. Mater. Degrad. 2, 21 (2018).

194. Frugier, P., Minet, Y., Rajmohan, N., Godon, N. \& Gin, S. Modeling glass corrosion with GRAAL. npj Mater. Degrad. 2, 35 (2018).

195. AMEC. Experimental Studies of the Chemical Durability of UK HLW and ILW Glasses Interim Progress Report. Report to RWM: RWM005105 (AMEC, 2015).

196. McGrail, B. P. et al. Near-field performance assessment for a low-activity waste glass disposal system: laboratory testing to modeling results. J. Nucl. Mater. 298 , 95-111 (2001).

197. Ojovan, M. I. \& Lee, W. E. Glassy wasteforms for nuclear waste immobilization. Metall. Mater. Trans. A 42, 837-851 (2011).

198. Frugier, P., Martin, C., Ribet, I., Advocat, T. \& Gin, S. The effect of composition on the leaching of three nuclear waste glasses: R7T7, AVM and VRZ. J. Nucl. Mater. 346, 194-207 (2005).

199. Luckscheiter, B. \& Nesovic, M. Long term corrosion behaviour of the WAK-HLW glass in salt solutions. Waste Manag 17, 429-436 (1997).

200. Raj, K. et al. Performance of high level waste forms and packages under repository conditions. Results of a previously unpublished CRP: Performance of High Level Waste Forms and Packages under Repository Conditions. https://inis.iaea. org/collection/NCLCollectionStore/_Public/42/024/42024380.pdf (1998).

201. Yalmali, V. S., Deshingkar, D. S. \& Wattal, P. K. Chemical durability of lead borosilicate glass matrix under simulated geological conditions. BARC--2002/E/005. https://inis.iaea.org/collection/NCLCollectionStore/_Public/34/073/34073636. $\mathrm{pdf} ? \mathrm{r}=1$ (2002)

202. Kaushik, C. P. et al. Barium borosilicate glass-a potential matrix for immobilization of sulfate bearing high-level radioactive liquid waste. J. Nucl. Mater. $\mathbf{3 5 8}$ 129-138 (2006).

203. Inagaki, Y. et al. Aqueous alteration of Japanese simulated waste glass P0798: effects of alteration-phase formation on alteration rate and cesium retention. $J$. Nucl. Mater. 354, 171-184 (2006).

204. IAEA. Assessment of Potential Matrixes for Intermediate Level Radioactive Waste at A1 NPP Decommissioning. End of Mission Report for project: SLR9011/01/01 (IAEA, 2015).

205. Ojovan, M. I. \& Lee, W. E. Self sustaining vitrification for immobilization of radioactive and toxic waste. Glass Technol. 44, 218-224 (2003).

206. Harrison, M. T. The effect of composition on short- and long-term durability of UK HLW glass. 2nd International Summer School on Nuclear Glass Wasteform: Structure, Properties and Long-Term Behavior, SumGLASS 2013. Proc. Mat. Sci. 7, 186-192 (2014).

207. Fisher, A. J., Harrison, M. T., Hyatt, N. C., Hand, R. J. \& Corkhill, C. L. The dissolution of simulant UK Ca/Zn-modified nuclear waste glass: the effect of increased waste loading. MRS Adv. 6, 95-102 (2021).

208. Iler, R. K. The Chemistry of Silica (Wiley,1979).

209. Gin, S., Beaudoux, X., Angéli, F., Jégou, C. \& Godon, N. Effect of composition on the short-term and long-term dissolution rates of ten borosilicate glasses of increasing complexity from 3 to 30 oxides. J. Non-Cryst. Solids 358, 2559-2570 (2012).

210. Fisher, A. J. et al. Short communication: the dissolution of UK simulant vitrified high-level-waste in groundwater solutions. J. Nucl. Mater. 538, 152245 (2020).

211. Fisher, A. J., Harrison, M. T., Hyatt, N. C., Hand, R. J. \& Corkhill, C. L. The dissolution of simulant UK Ca/Zn-modified nuclear waste glass: Insight into Stage III behavior. MRS Adv. 5, 103-109 (2020).

212. Aagaard, P. \& Helgeson, H. C. Thermodynamic and kinetic constraints on reac tion rates among minerals and aqueous solutions: I. Theoretical considerations. Am. J. Sci. 282, 237-285 (1982).

213. Lasaga, A. C. \& Kirkpatrick, R. J. Kinetics of geochemical processes. Rev. Mineral. 8, 135-169 (1981)

214. Gin, S., Jégou, C., Frugier, P. \& Minet, Y. Theoretical consideration on the application of the Aagaard-Helgeson rate law to the dissolution of silicate minerals and glasses. Chem. Geol. 255, 14-24 (2008). 
215. McGrail, B. P. et al. The structure of $\mathrm{Na}_{2} \mathrm{O}-\mathrm{Al}_{2} \mathrm{O}_{3}-\mathrm{SiO}_{2}$ glass: impact on sodium ion exchange in $\mathrm{H}_{2} \mathrm{O}$ and $\mathrm{D}_{2} \mathrm{O}$. J. Non-Cryst. Solids 291, 10-26 (2001).

216. Tournié, A. et al. Impact of boron complexation by Tris buffer on the initial dissolution rate of borosilicate glasses. J. Colloid Interface Sci. 400, 161-167 (2013).

217. Abraitis, P. K. et al. The kinetics and mechanisms of simulated British Magnox waste glass dissolution as a function of $\mathrm{pH}$, Silicic acid activity and time in low temperature aqueous systems. Appl. Geochem. 15, 1399-1416 (2000).

218. Pierce, E. M., Rodriguez, E. A., Calligan, L. J., Shaw, W. J. \& McGrail, B. P. An experimental study of the dissolution rates of simulated aluminoborosilicate waste glasses as a function of $\mathrm{pH}$ and temperature under dilute conditions. Appl. Geochem. 23, 2559-2573 (2008).

\section{ACKNOWLEDGEMENTS}

The authors gratefully acknowledge the financial support provided by the U.S. Department of Energy Waste Treatment and Immobilisation Plant Project, under the auspices of Project GLAD (Glass Leachability for Disposal Assessment). Albert Kruger, Office of River Protection, served as programme manager. Thorpe, C.L. and Corkhill, C.L. wish to acknowledge the Engineering and Physical Sciences Research Council (EPSRC) for the award of a David Clarke Research Fellowship under grant award number EP/S012400/1 and Early Career Research Fellowship under grant award number EP/N017374/1. Techniques and research highlighted in this review utilised the HADES/MIDAS facility at The University of Sheffield established with financial support from EPSRC and BEIS, under grant EP/T011424/1.

\section{AUTHOR CONTRIBUTIONS}

C.L.T. compiled the data and wrote the manuscript. C.L.C. and A.A.K. conceived the initial scope. A.J.F., S.A.W., R.J.H., N.C.H., C.I.P., J.J.N., A.A.K., M.S., D.S.K., C.L.A. and J.M. contributed their experience and expertise regarding the various standardised tests for glass dissolution. C.L.T, C.L.C, J.J.N., R.J.H. and C.I.P. contributed to the detailed revision of the manuscript. C.L.T., J.J.N. and S.A.W. contributed previously unpublished data. All authors contributed to critical review, edited the manuscript and approved the final document.

\section{COMPETING INTERESTS}

The authors declare no competing interests.

\section{ADDITIONAL INFORMATION}

Correspondence and requests for materials should be addressed to Clare L. Thorpe.

Reprints and permission information is available at http://www.nature.com/ reprints

Publisher's note Springer Nature remains neutral with regard to jurisdictional claims in published maps and institutional affiliations.

Open Access This article is licensed under a Creative Commons Attribution 4.0 International License, which permits use, sharing, adaptation, distribution and reproduction in any medium or format, as long as you give appropriate credit to the original author(s) and the source, provide a link to the Creative Commons license, and indicate if changes were made. The images or other third party material in this article are included in the article's Creative Commons license, unless indicated otherwise in a credit line to the material. If material is not included in the article's Creative Commons license and your intended use is not permitted by statutory regulation or exceeds the permitted use, you will need to obtain permission directly from the copyright holder. To view a copy of this license, visit http://creativecommons. org/licenses/by/4.0/.

(c) The Author(s) 2021 